Portland State University

PDXScholar

$1-1-2010$

\title{
Spatial Segregation of the Sexes in a Salt Marsh Grass Distichlis spicata (Poaceae)
}

Charlene Ashley Mercer

Portland State University

Follow this and additional works at: https://pdxscholar.library.pdx.edu/open_access_etds

Part of the Animal Sciences Commons, and the Biology Commons Let us know how access to this document benefits you.

\section{Recommended Citation}

Mercer, Charlene Ashley, "Spatial Segregation of the Sexes in a Salt Marsh Grass Distichlis spicata (Poaceae)" (2010). Dissertations and Theses. Paper 173.

https://doi.org/10.15760/etd.173

This Thesis is brought to you for free and open access. It has been accepted for inclusion in Dissertations and Theses by an authorized administrator of PDXScholar. Please contact us if we can make this document more accessible: pdxscholar@pdx.edu. 
Spatial Segregation of the Sexes in a Salt Marsh Grass Distichlis spicata (Poaceae)

by

Charlene Ashley Mercer

A thesis submitted in partial fulfillment of the requirements for the degree of

Master of Science

in

Biology

Thesis Committee:

Sarah Eppley, Chair

Mitchell Cruzan

Suzanne Estes

Portland State University

(C)2010 


\begin{abstract}
Understanding the maintenance of sexual systems is of great interest to evolutionary and ecological biologists because plant systems are extremely varied. Plant sexual systems have evolved to include not only complete plants with both male and female reproduction occurring on one plant (i.e., monoecious and hermaphroditic) but also plants with male and female function on separate plants (dioecious). The dioecious reproductive system can be used to test theories on niche differentiation given that having separate plants potentially allows for the exploitation of a broader niche. This increase in the realized niche is due to the ability for separate sexes to occupy different niches, which may occur in different physical habitats.
\end{abstract}

Some dioecious plants have been shown to occur in areas biased to nearly $100 \%$ male or nearly $100 \%$ female, called spatial segregation of the sexes (SSS). Occupying a broader niche could increase fitness in some species when the separation is used for one sex to gain access to resources that increase reproductive success and/or if the separation inhibits deleterious competition. These two mechanisms have been previously proposed for the evolution of SSS in dioecious plants. The first mechanism suggests that males and females have evolved to occupy different niches due to differences in reproduction (sexual specialization). The hypothesis for the sexual specialization mechanism is that females should have higher fitness in female-majority sites and males should have higher fitness in male-majority sites. The second mechanism states that males and females occupy different niches due to competition between the sexes (niche partitioning). The 
hypothesis for niche partitioning states that inter-sexual competition should decrease fitness more than intra-sexual competition. These mechanisms are not mutually exclusive.

In our research we use the salt-marsh grass Distichlis spicata as our study species because this plant is dioecious and because molecular markers have been developed to determine the sex of juvenile plants. These molecular markers are important for testing the niche partitioning hypothesis for SSS in juveniles. Furthermore, previous work in California has shown that plants occur in areas nearly $100 \%$ female and nearly $100 \%$ male called spatial segregation of the sexes (SSS). The previous research also showed that female-majority sites were higher in soil phosphorus than male-majority sites. We conduct all research, presented in the proceeding chapters, on Distichlis spicata in the Sand Lake estuary near Pacific City, Oregon and in the laboratory at Portland State University.

In Chapter 1 we used field data to answer two questions: (1) Does Distichlis spicata exhibit SSS in Oregon, and (2) If SSS is occurring, do differences occur in plant form and function (sexual specialization) in reproductive female and male plants in femalemajority and male-majority sites? We used a sex ratio survey and collected field data on reproductive males and females. Our results show that there are female-majority and male-majority areas and SSS is occurring in the Sand Lake Estuary. Results from our native plant data suggest that reproductive females perform better in female-majority sites compared to male-majority sites which could suggest that sexual specialization is 
occurring in females. We currently have a long term field reciprocal transplant experiment in place to further address this hypothesis.

In Chapter 2 we use field dada to address the following questions: (1) Does site-specific soil nutrient content occur in August, when females have set seed? (2) Does sex-specific mycorrhizal colonization occur in reproductively mature plants? (3) Does sex-specific mycorrhizal colonization vary seasonally in natural populations? Inside the roots of $D$. spicata a symbiotic relationship is formed between plant and arbuscular mycorrhizal fungus (AM). The AM- plant relationship has been shown to thrive in phosphorus limited areas because the mycorrhizal fungus increases nutrient access to the plant. We analyzed the results of the field soil nutrient content and mycorrhizal colonization in roots of native Distichlis spicata from male-majority and female-majority sites. The root colonization included staining roots with trypan blue and viewing sections of the roots under the microscope. Our results show that female- majority sites are higher in phosphorus and are found to have higher AM colonization than male- majority sites in the field.

In Chapter 3 we then reciprocally transplanted $D$. spicata plants in the field to address the following questions: (1) Does niche partitioning occur in D. spicata, and (2) If niche partitioning is occurring, which plants are competing more? Our reciprocal transplant experiment included seeds grown in intra-sexual, inter-sexual and no competition in cones, planted directly into the field, and allowed to grow for 15 months. After the 15 months was over we measured survival, dry weight and root/shoot ratio. The design of the experiment was to determine the effects of competition (intra-sexual and inter-sexual) 
and no competition on (single male and female) on survival, biomass and root/shoot ratios. Our results show that niche partitioning is occurring and plants in inter-sexual competition have significantly less biomass then intra-sexual competitors.

In, Chapter 4, we conduct a laboratory experiment to address the following questions: (1) Do plants show plasticity in their response to root exudates of the competing plant in regards to the sexual phenotype of the competitor? (2) Do plants show plasticity in their response to root exudates of the competing plant with respect to the relatedness of the competitor? We use sterile seeds grown in 24-well plates containing liquid media. For each competing plant, we picked plants up out of the wells and into the competing plants wells so that plants only experienced media that the competing plant had grown. At no time do roots ever come into contact with one another. We measured primary root length, number of lateral roots, the number of root hairs, root/shoot ratio and total dry weight. We analyzed the study two different ways, one for sexual type competition (inter-sexual, intra-sexual, none) and for plant relationship (KIN, STRANGER and OWN). The results for the sexual type competition found that inter-sexual competition was greater for root/shoot ratio and dry weight. The results for plant relationship competition found that kin plants had a significantly greater number of lateral roots and a significantly longer primary root.

The last chapter, Chapter 5, includes a summary of our conclusions. Our study found SSS occurring in the Sand Lake Estuary in Oregon with female-majority sites higher in phosphorus and root colonization higher in percent colonization of arbuscular 
mycorrhizal fungi compared to male-majority sites. Based on the sexual specialization hypothesis as a mechanism for SSS, we found that females had greater fitness in femalemajority sites compared to male-majority sites, suggesting that sexual specialization is occurring in reproductive females. We then tested the niche partitioning hypothesis for SSS, and we found consistent lab and field results suggesting that niche partitioning due to inter-sexual competition is an explanation for why females and males $D$. spicata plants spatially segregate themselves at the juvenile life history stage. Furthermore, we found that plants that have the same mother had a significantly greater number of lateral roots and a significantly longer primary root. These results suggest that KIN plants respond differently to one another compared to plants paired with a plant not from the same mother (STRANGER) or when the plant is alone (OWN). 
Dedicated to Ammon, Mom, Dad, Janine, Tony, Allen, Robbie, Grandma Jeanne, Papoo, Marleen, Lyndsey, Fred, Adelaide, Daniel, Shalom, Elsa, Jacob, Vanessa, Grandpa Larry, Grandma Marilyn, Brion, Katy, David, Pam, Mike, Jay, Amanda, Grandma Cheryl, Grandpa Don, Aunt Shelly, Aunt Twaney 


\section{Acknowledgements}

Thank you Sarah Eppley for giving me this opportunity, I will always hold this experience dear to my heart and will be able to use all of the knowledge I gained wherever I may go. 


\section{TABLE OF CONTENTS}

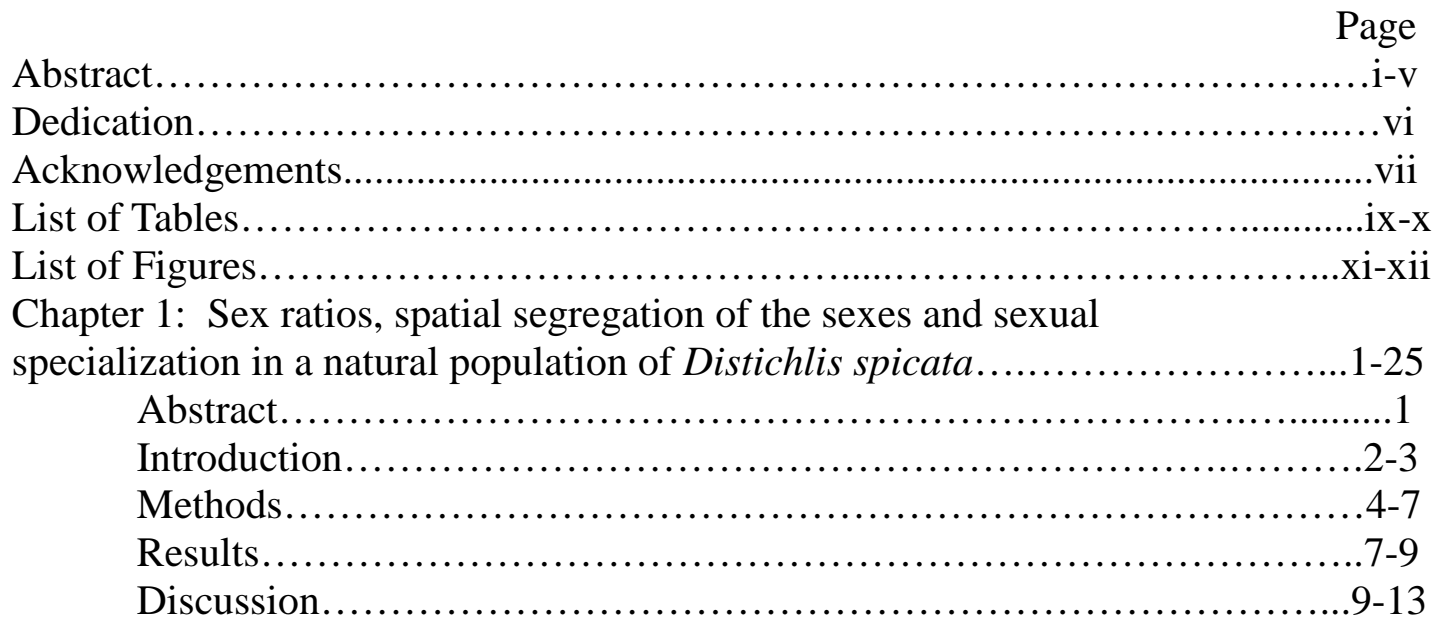

Chapter 2: Sex-specific variation in the interaction between Distichlis spicata

(Poaceae) and mycorrhizal fungi ...................................26-40

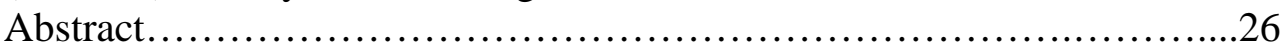

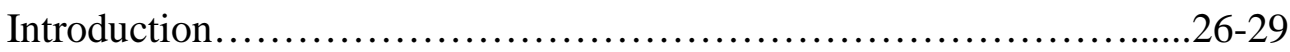

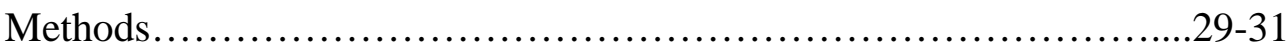

Results...........................................................

Discussion.........................................................

Chapter 3: Inter-sexual competition in a dioecious grass.....................41-62

Abstract............................................................. 41

Introduction..................................................... $41-44$

Methods............................................................... $44-49$

Results...............................................................

Discussion..................................................... $51-57$

Chapter 4: Kin recognition and inter-sexual competition in a

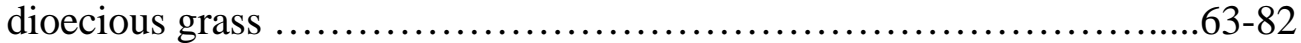

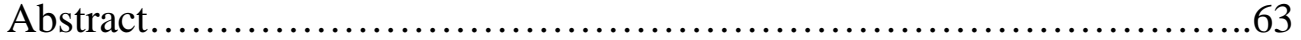

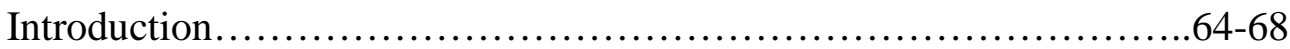

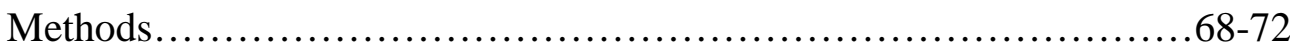

Results.........................................................

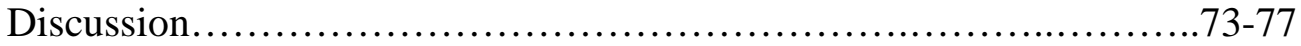

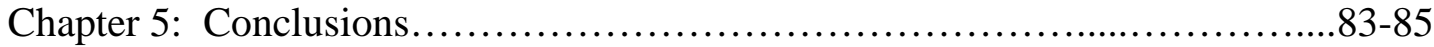

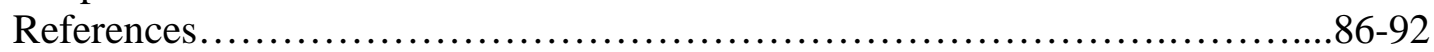




\section{LIST OF TABLES}

Page

Table 1-1. Habitat influence on sex ratio in two populations,

A.) Whalen Island and B) Sand Lake, of Distichlis spicata................15

Table 1-2. ANOVAs were used to determine the effects

of tiller sex (a fixed effect; male or female),

patch sex (a fixed effect; male-majority or

female-majority), the interaction of patch sex and

tiller sex, date (a fixed effect), the interaction of date

and tiller sex, the interaction of date and patch sex and

the interaction of patch sex, tiller sex and date on

A.) Chlorophyll, B.) Inflorescence weight, C.) Height, and

D.) Stalk weight. Significant $p$-values values are in bold; $(\mathrm{N}=514)$....

Table 1-3. ANOVAs were used to determine the effects of patch sex (a fixed effect; male-majority or female-majority, date (a fixed effect), and the interaction of date and patch sex on A.) Potential seed count B.) Actual seed count and C.) Total seed weight for female plants, significant p-values are in bold, $\mathrm{N}=514$

Table 1-4. ANOVAs were used to determine the effects of tiller sex (a fixed effect; male or female), patch sex (a fixed effect; male-majority or female-majority), the interaction of patch sex and tiller sex, date (a fixed effect), the interaction of date and tiller sex, the interaction of date and patch sex and the interaction of patch sex, tiller sex and date on fluorescence measurements

Table 2-1. Results of nested, mixed-model ANOVA to test how site (random, nested in site sex), site sex (fixed), and season (fixed) affected colonization by AMF in D. spicata plants collected from the field in 2008. Significant $P$-values are boldface. 


\section{LIST OF TABLES (continued)}

Page

Table 3-1. Logistic model used to determine the effects of competition type (inter-sexual, intra-sexual, and no competition), plant sex, site majority-sex, population, block (nested in population and site majority-sex), and interactions between these factors on survival of Distichlis spicata transplants after 15 months in the field. Non-significant interactions are not shown; see Data analysis section for details. $n=237$.

Table 3-2. Summary of ANOVA used to determine the effects of competition type (a fixed effect; inter-sexual, intra-sexual, and no competition), plant sex (a fixed effect), site majority-sex (a fixed effect), population (a random effect), block (a random effect; nested in population and site majority-sex) on dry weight and root/shoot ratio of transplants after 15 months in the field. $P$ values in bold are significant after the Bonferroni correction...

Table 4-1 Summary of ANOVA used to determine relatedness plant relatedness (KIN,STRANGER, OWN) on root/shoot ratio, total dry weight, root hairs, lateral roots and root length of root exudates trial after 7 days. $P$ values in bold are significant after the Bonferroni correction.

Table 4-2 Summary of ANOVA used to determine the effects of competition (INTRA, INTER, NONE), plant sex (male or female) and the interaction of competition and plant sex on root/shoot ratio, total dry weight, root hairs, lateral roots and root length of root exudates trial after 7 days. 


\section{LIST OF FIGURES}

Page

Figure 1-1. Map of a subsection of the Sand Lake, Oregon site showing skewed within population sex ratios

Figure 1-2. Sexual dimorphism in visual form of Distichlis spicata, an example of a female on the left and male on the right

Figure 1-3. The average sex male and female found in both male and female populations on Whalen Island and Sand Lake.

Figure 1-4. Graphs of mean measurements taken on Whalen Island and Sand Lake for males and females in high phosphorus (female-majority areas) and low phosphorus (male-majority areas) sites.

Figure 1-5. Chlorophyll measurement graphs summed for both males and females in both male-majority and female-majority habitats separated into dates.

Figure 1-6. Reproductive females from both male-majority and female-majority habitats assessed for seed potential, actual seed count and total weight of seed for July and September.

Figure 2-1. Percentage of analyzed root colonized by AMF $(+\mathrm{SE})$ in Distichlis spicata plants at Sand Lake, Oregon in (A) all sites for the 2 July 2008 collections when plants were green but not reproductive vs. the 21 August 2008 collections when females were setting seed ( $\mathrm{N}=128)$; (B) majority-female vs. majority-male sites for 2 July $(\mathrm{N}=128)$; and $(\mathrm{C})$ majority-female vs. majority-male sites for 21 August ( $\mathrm{N}=128)$. (D) Soil phosphorus levels (ppm) at majority-female and majority-male sites $(+\mathrm{SE})$ for 21 August $2008(\mathrm{~N}=48)$.

Figure 3-1. Dry weight (mean $\pm \mathrm{SE}$ ), $\mathrm{N}=78$, of Distichlis spicata transplants after 15 months in the field, grown in three competition treatments: None no competitor, Inter an inter-sexual competitor of the same species, or Intra an intra-sexual competitor of the same species. Different letters indicate significant differences $(\mathrm{P}<0.05)$ among treatments 
LIST OF FIGURES (continued)

Page

Figure 3-2. Root/shoot ratio (mean $\pm \mathrm{SE}$ ), $N=78$, of Distichlis spicata transplants after 15 months in the field, grown in three competition treatments: None no competitor, Inter an inter-sexual competitor of the same species, or Intra an intra-sexual competitor of the same species. Different letters indicate significant differences $(\mathrm{P}<0.05)$ among treatments

Figure 4-1 Graph of plant relatedness based on Lateral root number and Root length (mean $\pm \mathrm{SE}$ ) $\mathrm{N}=244$ after 7 days exposed to the sterile media of another root. The treatments employed for the relatedness analysis: Own, plant in own exudates; Kin, plant in exudates of kin; and Stranger, plant in exudates of stranger from same population. Different letters indicate significant differences $(\mathrm{P}<0.05)$ among treatments

Figure 4-2 Graph of competition analysis based on significant data for Dry weight and root/shoot ratio (mean \pm SE), $N=212$ after 7 days exposed to the sterile media of another root grown in three competition treatments: None no competitor, Inter an inter-sexual competitor of the same species, or Intra an intra-sexual competitor of the same species. Different letters indicate significant differences $(\mathrm{P}<0.05)$ among treatments 


\title{
Chapter 1: Sex ratios, spatial segregation of the sexes and sexual specialization in a natural population of Distichlis spicata
}

\author{
Abstract \\ It has been proposed that as plants evolved separate sexes (dioecy) they also evolved the \\ potential to increase their realized niche. This increase in realized niche is due to the \\ ability for separate sexes to occupy different niches, which may occur in different \\ physical habitats. Some dioecious plants have been shown to occur in areas biased to \\ nearly $100 \%$ male or nearly $100 \%$ female, called spatial segregation of the sexes (SSS). \\ Previous research has found that males and females exhibiting SSS occupy separate \\ habitats due to competition (niche partitioning hypothesis) or due to differences in \\ reproduction dependent nutrient acquisition between males and females (sexual \\ specialization hypothesis). These hypotheses are not mutually exclusive. The purpose of \\ our study was to determine whether SSS is occurring in the salt-marsh grass Distichlis \\ spicata in Oregon and determine whether differences occur in plant form and function \\ (sexual specialization) in reproductive female and male plants in female-majority \\ compared to male-majority habitats. Our results show that males and females show \\ extreme sex ratio bias and SSS. Furthermore, female plants were found to be significantly \\ more fit in female-majority habitats compared to male-majority habitats. We discuss the \\ implications for SSS in D. spicata and address the importance of finding habitat \\ differences in female reproductive success.
}




\section{Introduction}

Dioecious plants, distinguished as males and females on separate plants, have been proposed to have evolved due to selection for inbreeding avoidance (Charlesworth \& Charlesworth, 1978; Freeman et al. 1976; Freeman et al. 1997), sexual specialization (Charnov et al. 1976; Freeman et al. 1997) or due to the genetic control of sex expression (Charlesworth, 1999). In addition, because males and females are on separate plants, dioecious plants have the ability to utilize a greater niche. Previous studies have shown a female-biased sex ratio in one part of a habitat and a male-biased sex ratio in another area. This separation has been called "spatial segregation of the sexes" (SSS), (Bierzychudek and Eckhart, 1988) and has been documented in over 25 plant species from 18 families (Bierzychudek and Eckhart, 1988); (Lokker et al. 1994; Eppley et al. 1998a; Stark et al. 2005; Bertiller et al. 2002; Dudley 2006).

The distance between sexes may increase fitness in some species when the separation is used for one sex to gain access to resources that increase reproductive success and/or if the separation prevents deleterious competition (Bierzychudek and Eckhart, 1988). These two mechanisms have been previously proposed for SSS to occur in dioecious plants. One explanation suggests that plants occupy different niches because inter-sexual competition is greater than intra-sexual competition (niche partitioning). Alternatively, differences in resource utilization between the sexes (sexual specialization) may cause variation in reproductive success in different habitats (Bierzychudek and Eckhart 1988b). These mechanisms are not mutually exclusive. 
If SSS is observed, it would then be important to ask whether females and male are adapted to their respective habitat. Sexual dimorphism is the difference between secondary sexual characteristics in individual males and females. Sexually dimorphic traits in males and females can be assessed to determine whether sexual specialization is occurring in reproductive plants. Differences in traits that have a direct effect on fitness can be measured for males and females in male-majority and female-majority habitats.

In this study, our goal was to determine whether spatial segregation of the sexes is occurring in the salt-marsh grass Distichlis spicata in the Sand Lake Estuary, Oregon. Also we wanted to determine whether fitness differences arise between females in female-majority sites versus male-majority sites and males in female-majority and malemajority sites. Distichlis spicata is a halophylic, perennial, salt marsh grass that lives submerged in saline water throughout the year and is inundated by tides. Previous research has found that $D$. spicata exhibits SSS in California, with male and female genotypes found throughout the population in a gradient of nearly $100 \%$ male to nearly 100\% female (Bertness and Ellison 1987; Eppley et al. 1998b; Freeman et al. 1997). In this study we used field surveys to answer two questions: 1.) Does Distichlis spicata exhibit SSS in Oregon, and 2.) If SSS is occurring, do naturally occurring reproductive males and females have reproductive differences in male-majority and female-majority habitats? To answer these questions, we collected sex ratio data and data on height, weight, chlorophyll content, fluorescence and inflorescence weight in males and females.

\section{Materials and Methods}




\section{Study species}

Distichlis spicata (Poaceae) is a dioecious, perennial grass that is common in salt marshes on the east and west coasts of North America (Hitchcock 1971). In the western United States, D. spicata occupies middle and upper reaches of salt marshes, occurring at high densities with species such as Salicornia virginica, Triglochin maritima, and Plantago maritima (Mcdonald and Barbour 1974; Watson and Byrne 2009). Sexual reproduction in D. spicata involves wind dispersal of pollen (Beetle 1943; Hitchcock 1971) and water and bird dispersal of seeds (personal observations, S. Eppley), with extensive asexual propagation by rhizomes (Beetle 1943; Hitchcock 1971).

The research available on Distichlis spicata is widespread and ranging from physiological studies (Christman et al. 2009; Daines and Gould 1985; Ketchum et al. 1991), restoration (Elsey-Quirk et al. 2009; Marcum et al. 2007), associations with fungus (Eliades et al. 2007; Eppley et al. 2009a), use as a life stock crop (Bustan et al. 2005) and interactions with other plant species in wetland habitats (Hunter et al. 2008). Proposals for use of D. spicata as a model species in spatial segregation of the sexes (Eppley 2000) most notably for the sex specific molecular markers that have been developed, have also been suggested (Eppley et al. 2009b). Our research was conducted in the Sand Lake estuary near Pacific City, Oregon and in the laboratory at Portland State University.

\section{Population sex ratio at Sand Lake Estuary}

A sex ratio survey was conducted in the Sand Lake Estuary July 31, 2008 using a map to 
section off two populations; Whalen Island and Sand Lake. The sites were surveyed using a random number generator to select random locations on the map. For each location chosen, we then chose the closest flowering ramet (focal flowering ramet). We made a 10 diameter circle (neighborhood) around the focal flowering ramet and at 1 meter intervals along N,S,E,W directions we recorded the sex of the nearest flowering ramet. We continued our survey until we had selected 30 female focal plants and 30 male focal plants from Sand Lake Estuary. In total we determined the sex of 60 focal plants and 600 surveyed plants $(\mathrm{N}=660)$.

\section{Sex allocation in females and males in male- majority and female-majority habitats}

To determine whether naturally occurring males and females have reproductive differences in male-majority and female-majority habitats, we collected data on height, weight, chlorophyll content, fluorescence and inflorescence weight on plants from our field sites. While a reciprocal transplant experiment would ideally be used to estimate fitness of males and females in male- and female-majority sites, and we have such experiments set up, we are also interested in how naturally occurring males and females fare in different micro habitats, and thus used naturally occurring plants. On June 26, July 23 and September 4, 2009 (when native D. spicata had begun flowering, begun to set seed and fully set seed, respectively), native males and females were identified via purple stigma (female) and buff colored anthers (male) in the field (Figure 1-2). Next, 10 male and 10 female tillers from different plants were randomly chosen from 6 malemajority microhabitats and 6 female-majority microhabitats and had chlorophyll measurements taken three times and then averaged using a chlorophyll meter $(\mathrm{N}=514$; 
SPAD-502 Konica Minolta).

Each chlorophyll-measured plant was then labeled and brought back to the lab. In the lab each tiller's height was determined and each tiller was divided into inflorescence and stalk. Next, the separated inflorescence and stalk were dried in a drying oven at $60{ }^{\circ} \mathrm{C}$. After 7 days of drying, the inflorescence and stalk were weighed separately. Females from male-majority and female-majority habitats were brought back to the lab and inflorescences were assessed for potential seed count, actual seed count and total seed weight for each female for June, July and September. On July 20, 2009 and September 1, 2009 , fluoremeter measurements were taken during predawn for males and females in male-majority and female-majority patches.

\section{Data Analysis}

\section{Population sex ratio at Sand Lake Estuary}

To determine whether the sex ratio around male and female focal plants differed at the Sand Lake estuary and thus to assess within-population sex ratio variation, we used a oneway ANOVA (SAS Institute, 2007).

\section{Sex allocation in females and males in male-majority and female-majority habitats}

To determine whether males and females have differences in chlorophyll, inflorescence weight, height and stalk weight, we used a mixed model ANOVA to determine the effects of tiller sex (a fixed effect; male or female), patch sex (a fixed effect; male-majority or 
female-majority), the interaction of patch sex and tiller sex, date (a fixed effect), the interaction of date and tiller sex, the interaction of date and patch sex and the interaction of patch sex, tiller sex and date on A.) Chlorophyll, B.) Inflorescence weight, C.) Height, and D.) Stalk weight. In the ANOVA analysis the residuals were normally distributed and the variances were homogenous. For the ANOVA, if a significant difference was found for an effect, we used a post- hoc analysis (Tukey's tests) to determine which means were significantly different.

A mixed model ANOVA was used to determine the effect of majority habitat, date and the interaction of majority habitat by date on potential seed count, actual seed count and total seed weight for female $D$. spicata plants. In the ANOVA the residuals were normally distributed and the variances were homogenous. For the ANOVA, if a significant difference was found for an effect, we used a post- hoc analysis (Tukey's tests) to determine which means were significantly different.

A mixed-model ANOVA was used to determine the effect of tiller sex (a fixed effect; male or female), patch sex (a fixed effect; male-majority or female-majority), the interaction of patch sex and tiller sex, date (a fixed effect), the interaction of date and tiller sex, the interaction of date and patch sex and the interaction of patch sex, tiller sex and date on fluorescence. In the ANOVA the residuals were log transformed to meet the assumptions of ANOVA and the variances were homogenous.

\section{Results}




\section{Population sex ratio at Sand Lake Estuary}

The Sand Lake population showed within-population sex ratio bias: D. spicata neighborhoods around female plants had a mean sex ratio of $0.32 \pm 0.05$ (SE), while $D$. spicata neighborhoods around male plants had a mean sex ratio of $0.73 \pm 0.04$ (SE). An ANOVA suggests that sex ratios around female and male focal plants were significantly different $(N=60 ; F=46.20 ; \mathrm{df}=1 ; P<0.0001 ;$ Figure 1-1). Previous work in $D$. spicata populations on the west coast of the United States demonstrates that these populations are genetically diverse at small spatial scales (Eppley et al., 1998), suggesting that this pattern of within-population sex ratio bias is not created simply by clonal spread by a few genets but represents spatial segregation of hundreds of male and female genets.

Sex allocation in females and males in male-majority and female-majority habitats

Date, tiller sex and the interaction of date by tiller sex had a significant effect on chlorophyll (Table 2-2 A; Figure 1-4). Post hoc analysis suggests that females have less chlorophyll then males and that both males and females in male-majority and femalemajority habitats have significantly less chlorophyll from June to July and then in September (Figure 1-5). Tiller sex had a significant effect on height with females being significantly shorter then males (Table 1-2). Interestingly, all plants in female-majority habitats were the same height as plants in male-majority habitat as shown via the posthoc analysis. For stalk weight, date showed that both June and September produced less heavy plants compared to July (Table 1-2).

For all reproductive females sampled, date had a significant effect on both the actual seed 
count and total seed weight with the actual seed count and total seed weight being higher in September then in July. Patch sex was significant for potential seed count; actual seed count and total seed weight and the post- hoc analysis showed that female-majority sites were greater for each trait compared to male-majority habitats (Table 1-3). No effect tests were found to be significant for fluoremeter measurements.

\section{Discussion}

\section{Population sex ratio at Sand Lake Estuary}

The spatial relationship of male and female plants has great implications for reproductive success at the population level. If females and males are spaced far away from one another, pollen might not reach the stigma as easily as if they co-occurred in the same patch. Conversely, when males and females are close to one another, competition and/or depletion of resources could cause a decrease in plant fitness (Bierzychudek and Eckhart, 1988). Determining whether D. spicata exhibits spatial segregation of the sexes is an important step in understanding population dynamics in this dioecious plant. Our results show that populations of Distichlis spicata at Sand Lake and Whalen Island, Oregon have a distinct pattern of sex ratios bias. Our results suggest that these two populations exhibit spatial segregation of the sexes, with distinct patches with male-majorities and distinct patches with female-majorities (Figure 1-1). These data correspond with previous data in this species (Eppley, 1998) and data from other dioecious species (Lokker et al. 1994; Stark et al. 2005; Bertiller et al. 2002; Dudley 2006).

Sex allocation in females and males in male-majority and female-majority patches 
Spatial segregation of the sexes in D. spicata suggests that males and females of this species may differ in the nutrients they need to optimally reproduce (Sexual specialization) and or competition is occurring and plants occupy different habitats to prevent deleterious competition. We estimated chlorophyll content, height and stalk weight. Our data suggests that there are differences in chlorophyll content between males and females during reproductive periods in June, July and September. A decrease in the SPAD value computed by the chlorophyll meter indicates a decrease in chlorophyll content and nitrogen concentration and can be used as a measure of plant stress. For both males and females there was a significant decrease in chlorophyll from June to July and September suggesting a decrease in nitrogen for both males and females as they go through different reproductive stages. Males and females were also shown to have significant differences in chlorophyll content. Males had significantly higher chlorophyll content then females which indicates males overall are less stressed then females, most likely because reproduction is more costly for females (Eppley, 2006) (Table 1-2).

Females were found to be significantly shorter than males (Table 1-2). This result is consistent with most angiosperms suggesting that reproduction is more efficient when males are taller than females so that pollen can be distributed via wind and gravity. This data could also suggest that females are allocating more resources to reproductive output and less resource allocation to height. While there was no significant difference found between stalk weights of males and females. The sampling date was significant for all males and female pooled for June, July or September. This result suggesting that resource allocation for the stalk of the plant is the same for both males and females. 


\section{Sexual specialization}

When males and females occupy a habitat dominated by the opposite sex, we expect to see fitness decreases. Our measurement of fitness for males and females was the weight of the inflorescence (reproductive structure). Male plants in both male-majority and female- majority sites had the same inflorescence weight suggesting that the pollen production based on total weight of the inflorescence is consistent in both habitats. Females in female-majority habitats had significantly heavier inflorescence compared to females in male-majority habitats suggesting that seed set based on total weight of the inflorescence is significantly different in both habitats.

We then further separated the female inflorescences into potential seed set ability, actual seed set and total seed weight for females in female-majority habitats compared to malemajority habitats and found these all to be significantly higher in female-majority habitats compared to male-majority habitats. These results suggest that females have significantly higher fitness in female-majority sites compared to male-majority sites, despite the fact that they were farther from potential sources of pollen in male-majority sites, and previous research in D. spicata suggests that this system is pollen limited (Eppley 2005). Interestingly, males were not affected differently by site sex, suggesting that either we did not fully test what limits reproductive success in males or reproductive success for males is adequate in both sites. The results for female plants can be explained by the sexual specialization hypothesis stating that a plant should have higher fitness at the site with the same sex compared to a site with the opposite sex. These results are important in 
understanding if males and females have higher fitness due to spatial segregation of the sexes, which it appears that females do have higher fitness due to SSS.

A recent study on the dioecious herb Mercurialis annua showed differences in growth and reproduction for female and male plants that were grown in previous soil that had been occupied by female plants and previous soil occupied by with male plants (SanchezVilas and Pannell, 2010). The authors suggest that males and females are differentially modifying the soil they grow in due to sex-specific differences in nutrient utilization. Our results could be explained in this context, suggesting that differences in nutrient use are found in both male majority and female-majority habitats. Previous research on $D$. spicata in California showed that levels of $\mathrm{P}$, soluble $\mathrm{K}, \mathrm{Zn}, \mathrm{Fe}, \mathrm{Cu}$, exchangeable $\mathrm{Ca}$, exchangeable $\mathrm{Mg}$, exchangeable $\mathrm{Na}$, and organic matter are significantly greater, and percent sand is significantly less, in low-elevation, majority-female sites within the marsh (Eppley 2000). The findings of this study are similar to other studies that have found differences in male and female resource use in dioecious plants (Freeman et al. 1976; Dawson and Bliss, 1989; Dawson and Ehleringer, 1993).

\section{Conclusions}

Distichlis spicata exhibits SSS in two populations as was seen with male-majority and female-majority habitats. Spatial segregation of the sexes is likely to be driven by a combination of niche partitioning and sexual specialization at different stages of reproduction. Our results suggest that native, reproductive females have greater fitness in female-majority sites compared to male-majority sites. As our results were performed on 
native plants, in the field, it is very likely that sexual specialization is occurring in reproductive females. We have a long term reciprocal transplant experiment currently in the field to further address the niche partitioning and sexual specialization hypotheses on reproductive $D$. spicata plants. 
Figure 1-1. Map of a subsection of the Sand Lake, Oregon site showing skewed withinpopulation sex ratios. Orange areas represent areas with high concentrations of female Distichlis spicata plants (sex ratios $=0.0-0.2$ ) and are frequent. Dark blue areas represent areas with high concentrations of male $D$. spicata plants $(0.8-1.0)$ and dominate most of this marsh. Areas with even sex ratios (yellow; sex ratio $=0.4-0.6$ ) are fairly rare. The map was generated using the program ArcGIS 9.2 (ESRI, Redlands, California, USA).

Figure 1-2. Sexual dimorphism in visual form of Distichlis spicata, an example of a female on the left and male on the right.

Figure 1-3. The average sex male and female found in both male and female populations on Whalen Island and Sand Lake.

Figure 1-4. Graphs of mean measurements taken on Whalen Island and Sand Lake for males and females in high phosphorus (female-majority areas) and low phosphorus (male-majority areas) sites. A.) Inflorescence weight for June, B.) Chlorophyll for June, C.) Inflorescence for July, D.) Chlorophyll for July, E.) Inflorescence weight for September, F.) Chlorophyll for September, G.) Height for June, H.) Stalk weight for June, I.) Height for July, J.) Stalk Weight for July, K.) Fluorescence measurements for July, L.) Height for September, M.) Stalk weight for September, N.) Fluorescence measurements for September.

Figure 1-5. Chlorophyll measurement graph summed for both males and females in both male- and female-majority habitats separated into June, July and September.

Figure 1-6. Reproductive females from both male-majority and female-majority habitats assessed for A.) Seed potential for both male-majority and female-majority areas B.) Seed potential for July and September both sites pooled together. C.) Actual seed count for both male-majority and female-majority areas D.) Actual seed count for July and September both sites pooled together. E.) Total seed weight for both male-majority and female-majority areas, F.) Total seed weight for July and September both sites pooled together. 
Table 1-1. Habitat influence on sex ratio in two populations, A.) Whalen Island and B) Sand Lake, of Distichlis spicata.

A. Whalen Island

\begin{tabular}{||l|l|l|l|}
\hline Habitat- & Male (No.) & Female (No.) & Male/Female \\
\hline $\begin{array}{l}\text { Female- Majority } \\
\text { habitat }\end{array}$ & 102 & 174 & 0.59 \\
\hline $\begin{array}{l}\text { Male- Majority } \\
\text { habitat }\end{array}$ & 229 & 37 & 6.19 \\
\hline
\end{tabular}

B. Sand Lake

\begin{tabular}{||l|l|l|l|}
\hline Habitat & Male (No.) & Female (No.) & Male/Female \\
\hline $\begin{array}{l}\text { Female- Majority } \\
\text { habitat }\end{array}$ & 64 & 189 & 0.34 \\
\hline $\begin{array}{l}\text { Male- Majority } \\
\text { habitat }\end{array}$ & 157 & 98 & 1.60 \\
\hline
\end{tabular}


Table 1-2. ANOVAs were used to determine the effects of tiller sex (a fixed effect; male or female), patch sex (a fixed effect; malemajority or female-majority), the interaction of patch sex and tiller sex, date (a fixed effect), the interaction of date and tiller sex, the interaction of date and patch sex and the interaction of patch sex, tiller sex and date on

A.) Chlorophyll, B.) Inflorescence weight, C.) Height, and D.) Stalk weight. Significant p-values values are in bold; (N=514).

\begin{tabular}{|c|c|c|c|c|c|c|c|c|c|c|c|c|}
\hline \multirow[t]{2}{*}{ Source } & \multicolumn{3}{|c|}{ A.) Chlorophyll } & \multicolumn{3}{|c|}{ B.) Inflorescence weight } & \multicolumn{3}{|c|}{ C.) Height } & \multicolumn{3}{|c|}{ D.) Stalk weight } \\
\hline & $\mathrm{df}$ & $\mathrm{F}$ & $\mathrm{P}$ & $\mathrm{df}$ & $\mathrm{F}$ & $\mathrm{P}$ & df & $\mathrm{F}$ & $\mathrm{P}$ & df & $\mathrm{F}$ & $\mathrm{P}$ \\
\hline tiller sex & 1 & 5.46 & 0.0198 & 1 & 108.07 & $<.0001$ & 1 & 127.90 & $<.0001$ & 1 & 0.90 & 0.34 \\
\hline patch sex & 1 & 0.27 & 0.61 & 1 & 15.61 & $<.0001$ & 1 & 0.18 & 0.67 & 1 & 0.89 & 0.35 \\
\hline patch sex*tiller sex & 1 & 0.23 & 0.63 & 1 & 15.88 & $<.0001$ & 1 & 0.50 & 0.48 & 1 & 1.31 & 0.25 \\
\hline date & 2 & 43.93 & $<.0001$ & 2 & 8.97 & 0.0001 & 2 & 15.46 & $<.0001$ & 2 & 17.14 & $<.0001$ \\
\hline date*tiller sex & 2 & 8.91 & 0.0002 & 2 & 44.09 & $<.0001$ & 2 & 0.63 & 0.53 & 2 & 0.44 & 0.64 \\
\hline date ${ }^{*}$ patch sex & 2 & 0.41 & 0.67 & 2 & 6.74 & 0.0013 & 2 & 3.06 & 0.0476 & 2 & 4.00 & 0.0189 \\
\hline $\begin{array}{l}\text { patch sex*tiller } \\
\text { sex }^{*} \text { date }\end{array}$ & 2 & 0.67 & 0.51 & 2 & 5.41 & 0.0047 & 2 & 0.14 & 0.87 & 2 & 0.65 & 0.52 \\
\hline
\end{tabular}


Table 1-3. ANOVAs were used to determine the effects of patch sex (a fixed effect; malemajority or female-majority, date (a fixed effect), and the interaction of date and patch sex on A.) Potential seed count B.) Actual seed count and C.) Total seed weight for female plants, significant $\mathrm{p}$-values are in bold, $\mathrm{N}=514$.

\begin{tabular}{|c|c|c|c|c|c|c|c|c|c|}
\hline \multirow[t]{2}{*}{ Source } & \multicolumn{3}{|c|}{ A.) Potential seed count } & \multicolumn{3}{|c|}{ B.) Actual seed count } & \multicolumn{3}{|c|}{ C.) Total seed weight } \\
\hline & $\mathrm{P}$ & & & df & $\mathrm{F}$ & $\mathrm{P}$ & df & $\mathrm{F}$ & $\mathrm{P}$ \\
\hline date & 1 & 0.39 & 0.54 & 1 & 19.68 & $<.0001$ & 1 & 65.89 & $<.0001$ \\
\hline patch sex & 1 & 14.36 & 0.0004 & 1 & 43.63 & $<.0001$ & 1 & 42.86 & $<.0001$ \\
\hline $\begin{array}{l}\text { date }{ }^{*} \text { patch } \\
\text { sex }\end{array}$ & 1 & 0.05 & 0.82 & 1 & 0.03 & 0.86 & 1 & 9.934 & 0.0025 \\
\hline
\end{tabular}


Table 1-4. ANOVAs were used to determine the effects of tiller sex (a fixed effect; male or female), patch sex (a fixed effect; male-majority or female-majority), the interaction of patch sex and tiller sex, date (a fixed effect), the interaction of date and tiller sex, the interaction of date and patch sex and the interaction of patch sex, tiller sex and date on fluorescence measurements.

\begin{tabular}{lccc}
\hline \multirow{2}{*}{ Source } & \multicolumn{3}{c}{ A.) Fluoremeter measurement } \\
& df & F & P \\
\hline tiller sex & 1 & 2.48 & 0.12 \\
patch sex & 1 & 0.64 & 0.43 \\
patch sex*tiller sex & 1 & 0.04 & 0.84 \\
date & 1 & 3.49 & 0.06 \\
date*tiller sex & 1 & 0.12 & 0.73 \\
date*patch sex & 1 & 0.16 & 0.69 \\
patch sex*tiller & 1 & 0.03 & 0.88 \\
sex*date & & &
\end{tabular}


Figure 1-1

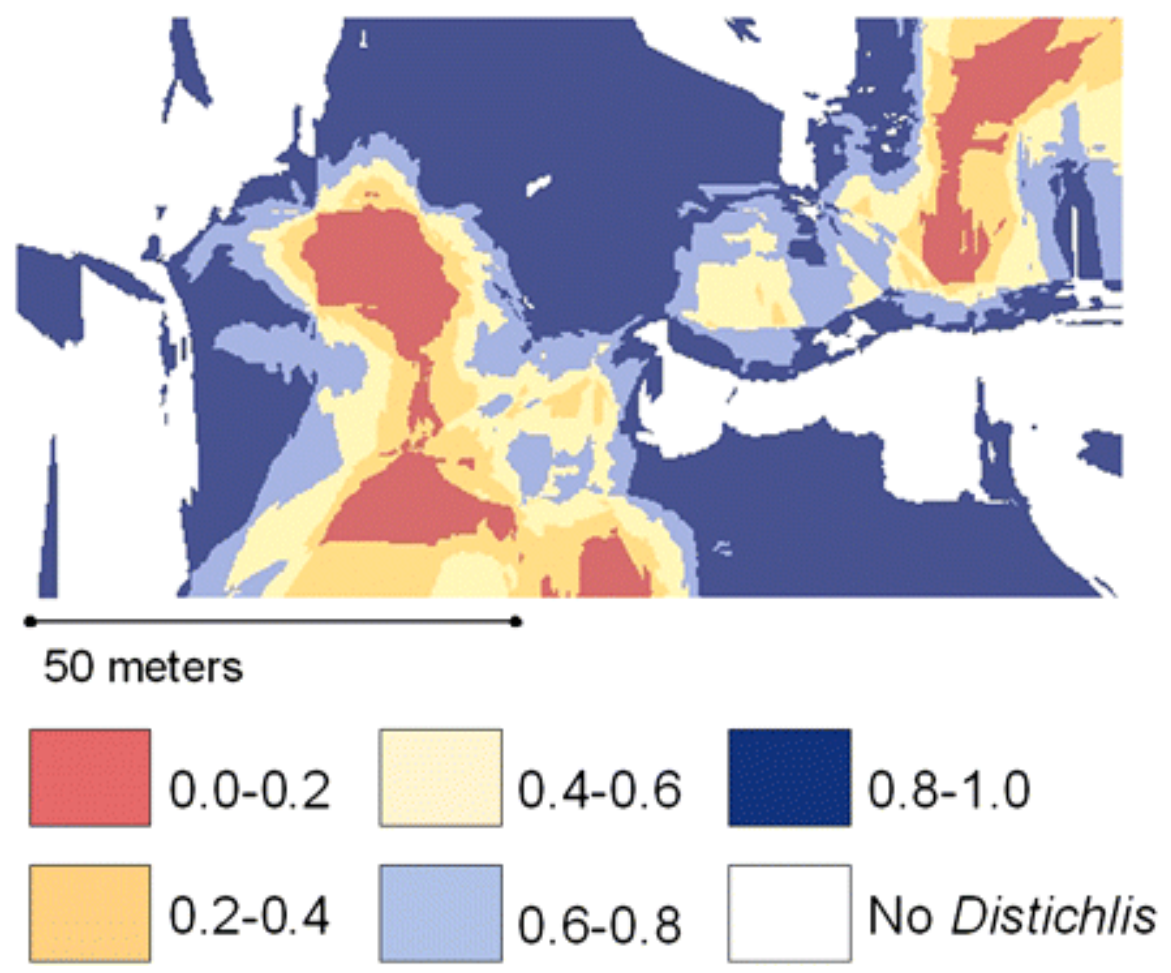


Figure 1-2

Female

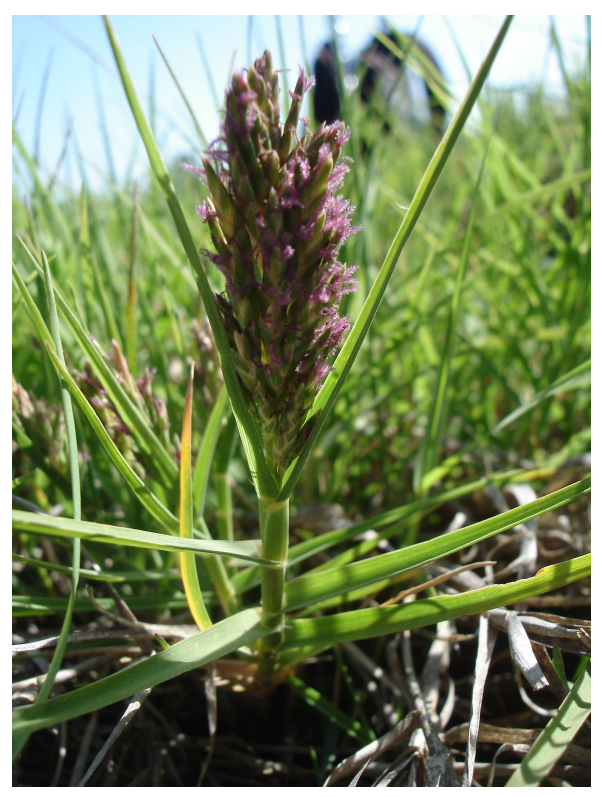

Male

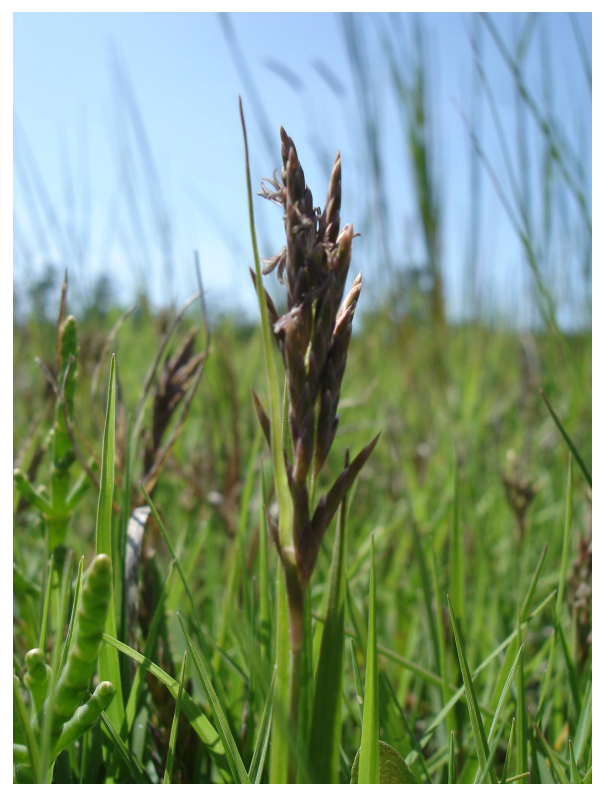


Figure 1-3

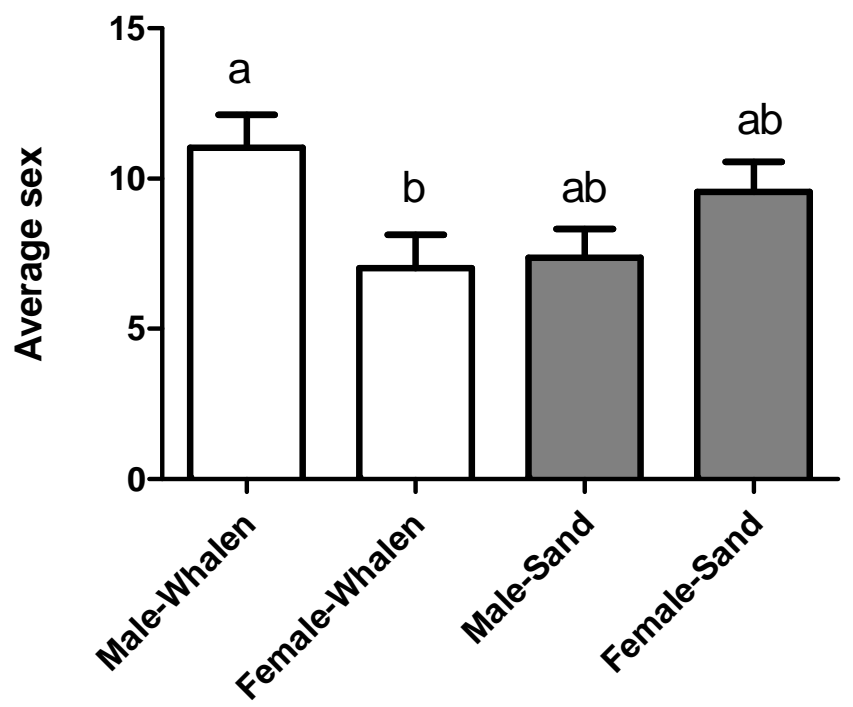


Figure 1-4
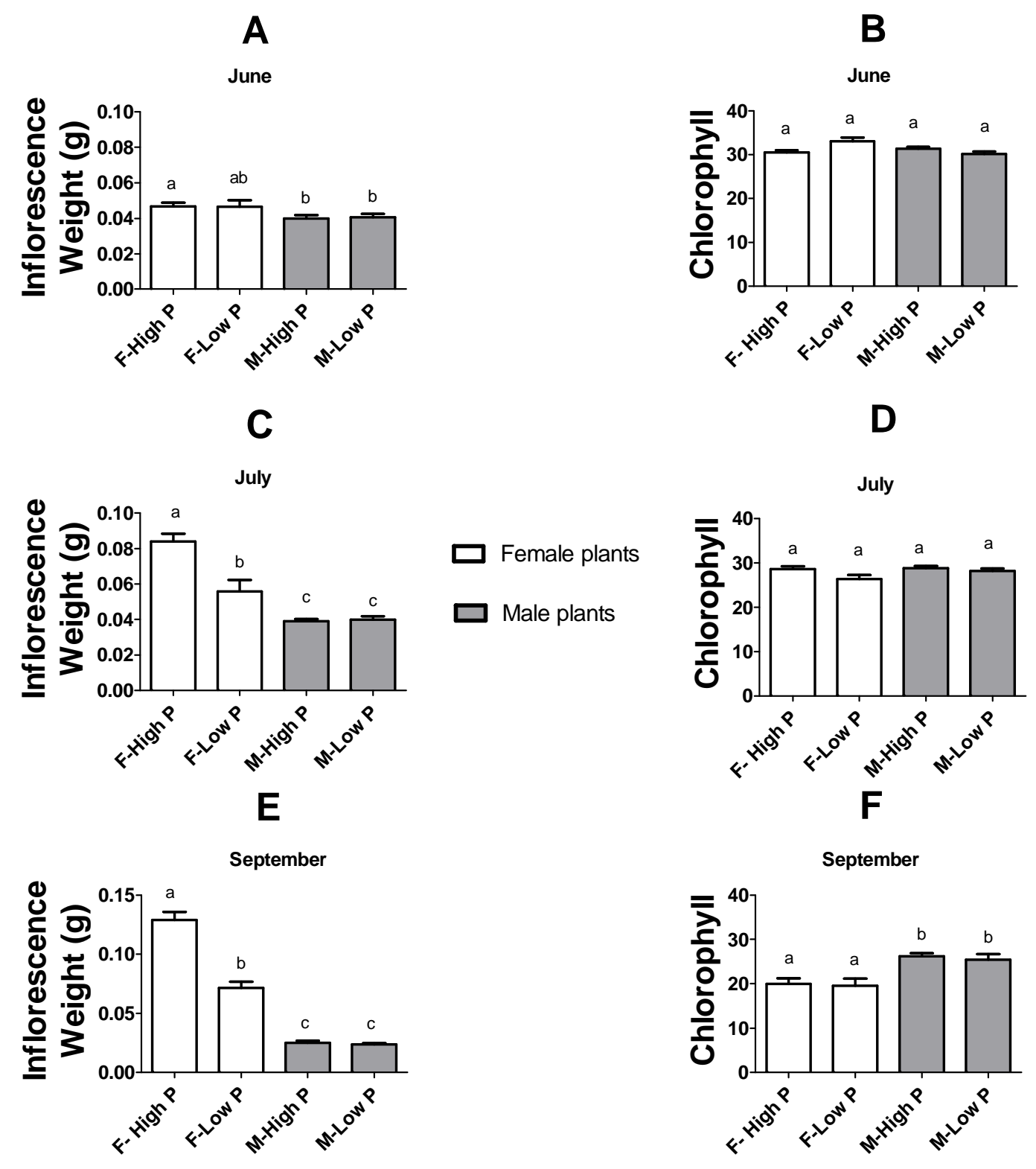
Figure 1-4 (continued)
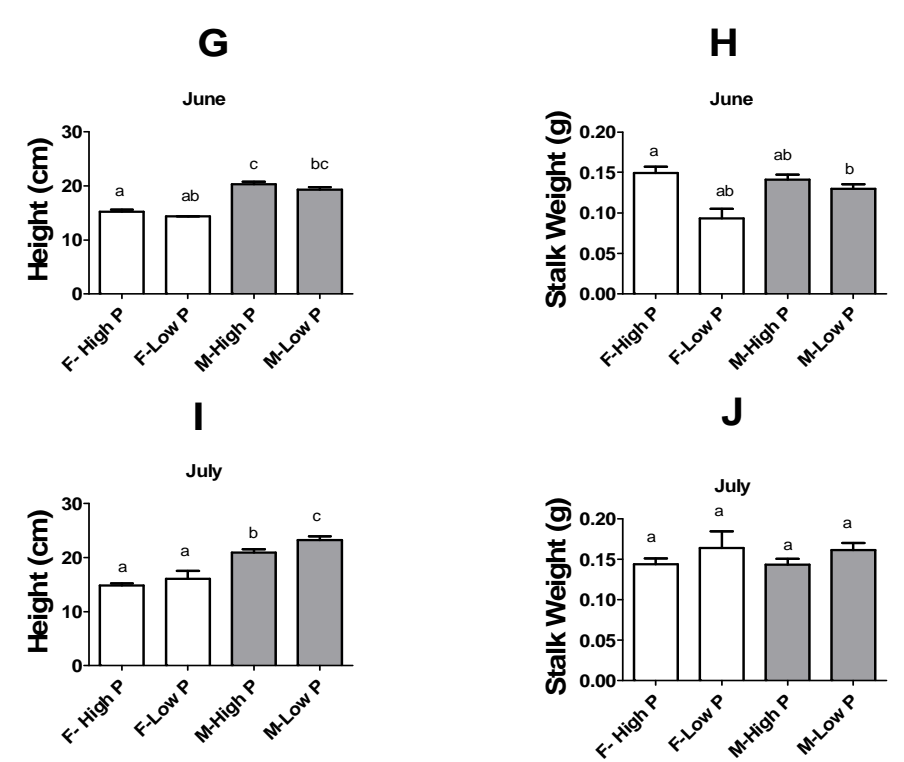

L
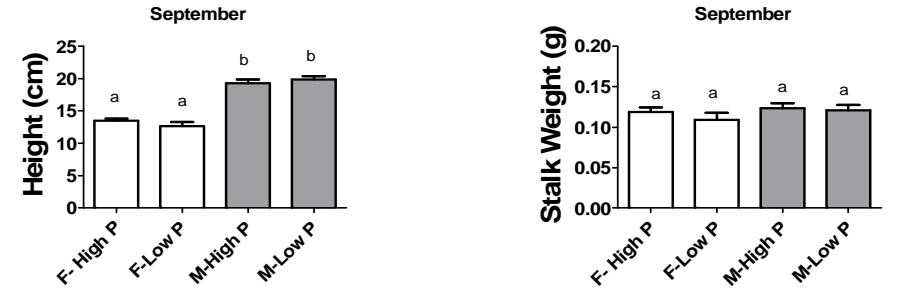

口 Female plants

$\square$ Male plants

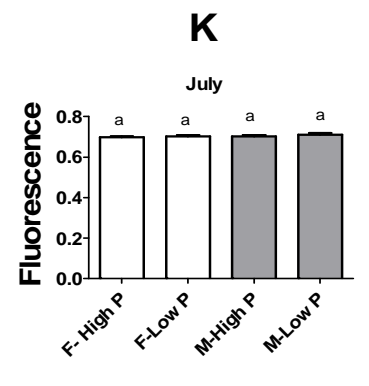

$\mathbf{N}$

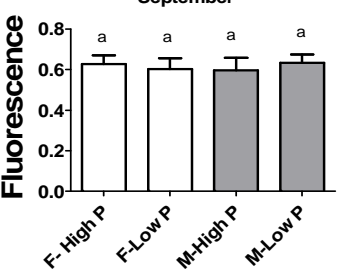


Figure 1-5

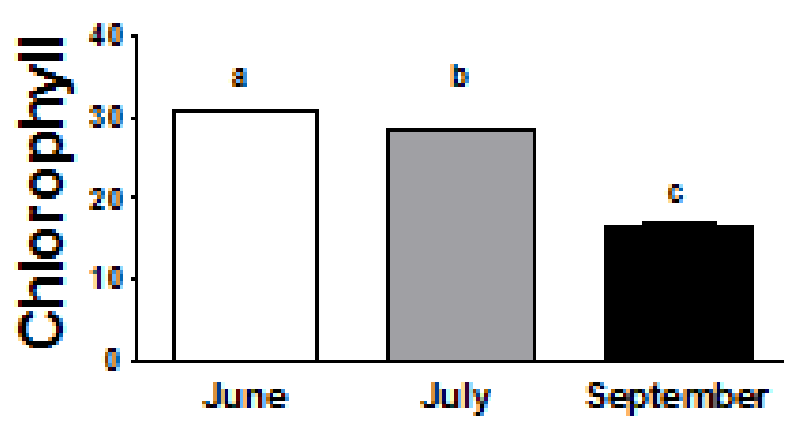


Figure 1-6

A

B
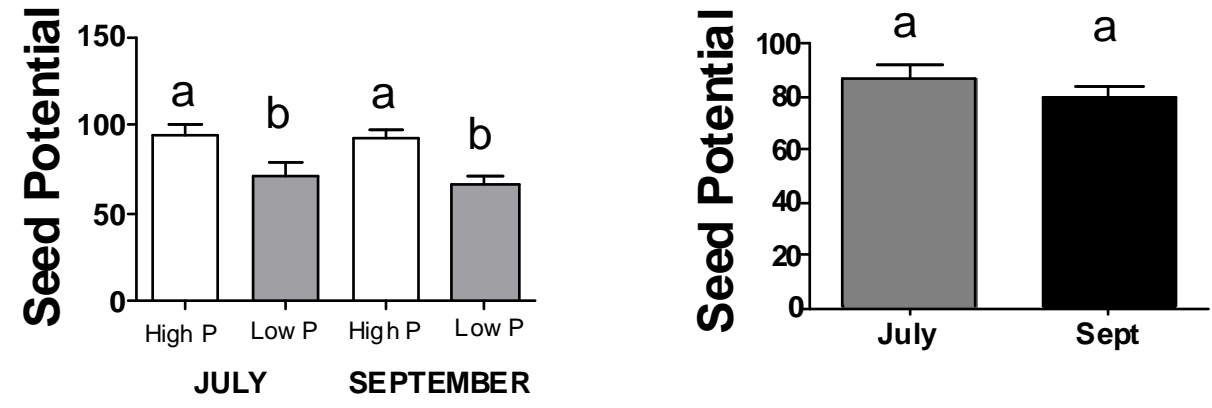

C

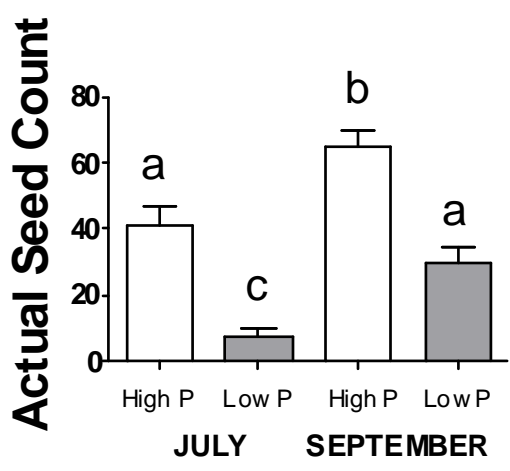

D

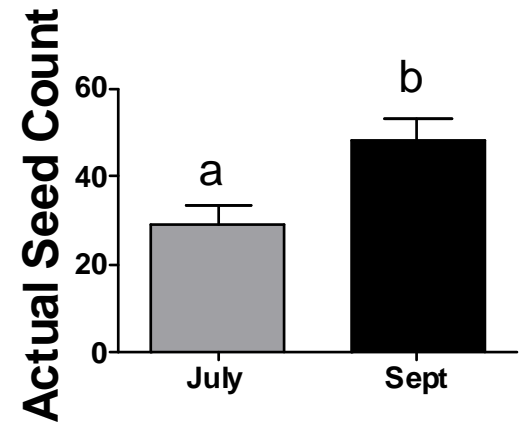

E

F
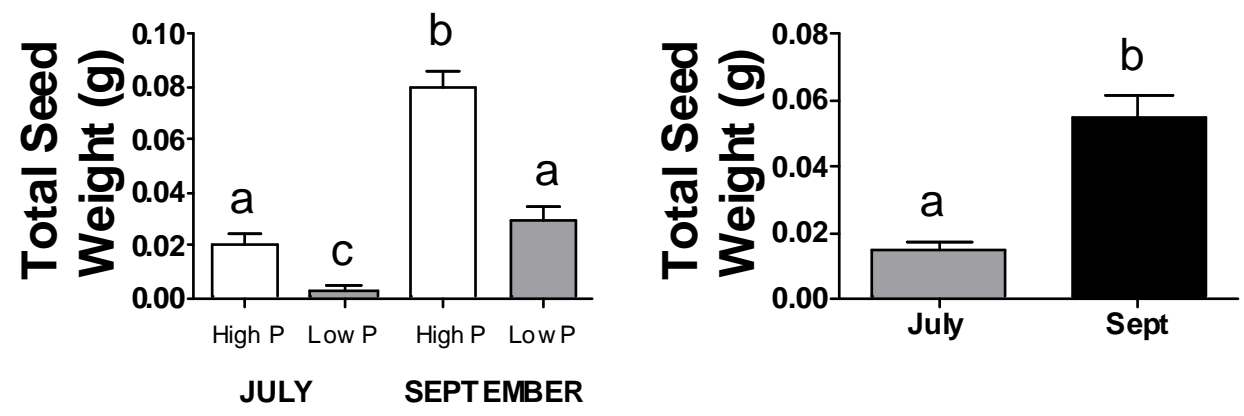


\title{
Chapter 2: Sex-specific variation in the interaction between Distichlis spicata (Poaceae) and mycorrhizal fungi
}

\begin{abstract}
Associations between mycorrhizal fungi and plants can influence intraspecific competition and shape plant population structure. While variation in plant genotypes is known to affect mycorrhizal colonization in crop systems, little is known about how genotypes affect colonization in natural plant populations or how plant sex might influence colonization with mycorrhizal fungi in plant species with dimorphic sexual systems. In this study, we analyzed mycorrhizal colonization in males and females of the wetland dioecious grass Distichlis spicata, which has spatially segregated sexes. Our results suggest that $D$. spicata males and females interact with mycorrhizal fungi differently. We discuss the implications for the role of this sex-specific symbiotic interaction in the maintenance of the intraspecific sex ratio bias of $D$. spicata.
\end{abstract}

\section{Introduction}

Mycorrhizal fungi form symbiotic relationships with the vast majority of flowering plants (Newman and Reddell, 1987), and while the relationship has generally been interpreted to be mutualistic, it may vary along a continuum from mutualism to parasitism (Johnson et al., 1997). The benefit for fungi in this symbiosis is primarily direct carbohydrate gain from plant hosts (Finlay and Söderström, 1992), while the benefit for plants is more complex and may include increased uptake of limited nutrients (Marschner and Dell, 1994), as well as protection from pathogenic root fungi (Newsham 
et al., 1995), protection from drought stress (Allen and Allen, 1986), and improved soil structure (Miller and Jastrow, 2000). As a result of the effects of this symbiosis on plant fitness, mycorrhizal fungi can influence plant population structure (e.g., Eissenstat and Newman, 1990; Allsopp and Stock, 1992). In particular, because mycorrhizal relationships increase nutrient access in nutrient poor soils, mycorrhizal associations have been found to increase intraspecific competition (e.g., Facelli et al., 1999; Pietikäinen and Kytöviita, 2007). Mycorrhizal interactions also generally increase size inequalities among plants within species (Moora and Zobel, 1998) and thus reproductive inequalities (Shumway and Koide, 1995). However, the role of mycorrhizal fungi in shaping plant populations is expected to be more complex than purely a density-dependent phenomenon because interactions between mycorrhizal fungi and plants are expected to vary depending on plant genotype (e.g., Azcon and Ocampo, 1981; Heckman and Angle, 1987; Yao et al., 2001; Singh et al., 2002). Data on the variation in mycorrhizal colonization with genotype currently comes from crop systems (reviewed by Smith and Goodman, 1999), but natural populations are expected to have a similar pattern.

Differential response by male and female plants to mycorrhizal infection is one genotype-specific aspect of mycorrhizal-plant relationships that has been examined, but for which evidence has not been previous found (Gehring and Whitham, 1992; Varga and Kytöviita, 2008). However, dioecious species with biased sex ratios have not been examined as far as we are aware. Sex-specific interactions between angiosperms and mycorrhizal fungi could have significant impacts on plant population sex ratios, plant population structures, and the coevolution of the fungus-plant relationship. Sexual 
dimorphism - differences between male and female individuals in primary and secondary sexual characters-is thought to have evolved in higher plants due to sex-specific selection in which males and females experience different selection pressures (Smouse and Meagher, 1994). Over evolutionary time, this mode of selection leads to differentiation of males and females of the same species in morphological, physiological, and life-history traits (see Dawson and Geber, 1999; Delph, 1999; Eckhart, 1999 for reviews). Sex-specific differences in morphology, physiology, and life-history are likely to lead to differences in how males and females interact with other organisms and such sex-specific biotic interactions, including variation in responses to herbivory, parasitism, and competition, have been measured in a number of plant species and have the potential to influence sex ratios (Ågren et al., 1999).

In the present study, we analyzed mycorrhizal colonization in roots of male and female Distichlis spicata plants grown in natural populations to address the following questions: (1) Does sex-specific mycorrhizal colonization occur in reproductively mature plants? (2) Does sex-specific mycorrhizal colonization vary seasonally in natural populations?

Distichlis spicata is an ideal model system for our study. First, $D$. spicata has spatially segregated sexes (SSS) within a population (Freeman et al., 1976; Eppley et al., 1998). Habitats in the marsh that have lower nutrient concentrations have adult sex ratios near $100 \%$ male, and with higher nutrient concentrations have adult sex ratios near $100 \%$ female (Eppley, 2000, 2001). The sex ratio bias found within populations occurs for both ramets and genets, regardless of flowering status (Eppley et al., 1998). Consequently, the 
sex ratio bias found in $D$. spicata has the potential to be influenced by sex-specific biotic interactions. Second, there are sex-specific differences in seed germination, seedling survival and seedling competitive effects in this species (Eppley, 2000, 2001, 2006), suggesting that sex-specific differences occur at early stages in this species. Third, previous inter-sexual competition experiments in D. spicata suggest that sex-specific biotic interactions might occur (Eppley, 2006), D. spicata is known to be colonized by arbuscular mycorrhizal fungi (AMF) (Allen and Cunningham, 1983; Cooke and Lefor, 1990; Hoefnagels et al., 1993; Johnson-Green et al., 1995), and AMF are known to have significant effects on measures of fitness in D. spicata (Allen and Cunningham, 1983). Fourth, a sex-linked marker is available to determine the sex of pre-reproductive individuals (Eppley et al., 2009).

\section{Materials and Methods}

Species Used and Study Sites

We conducted the fieldwork for this study at Whalen Island and Sand Lake Recreational Site in Pacific City, Oregon. D. spicata is a dioecious, perennial grass common in salt marshes on the east and west coasts of North America (Hitchcock 1971). Sexual reproduction in D. spicata involves wind dispersal of pollen (Beetle 1943; Hitchcock 1971) and water dispersal of seeds (personal observations, S. Eppley), with extensive asexual propagation by rhizomes (Beetle 1943; Hitchcock 1971).

Field collection of roots 2008 (Arbuscular Mycorrhizal fungi Root Colonization)

To determine how AMF colonization in male and female D. spicata varies 
seasonally, we collected roots from the population in the Sand Lake estuary during two time periods. We chose times during the summer and early fall, as these periods have been shown to be most active for AMF colonization in salt marsh systems (van Duin et al., 1990; Carvalho et al., 2001). Eight permanent plots were established, four in randomly chosen female-majority sites and four in randomly chosen male-majority sites, previous determined as described earlier). On 2 July, when plants were green but not flowering, the first collection of roots was made. Roots from eight plants were collected at least $1 \mathrm{~m}$ apart at each of the four male-majority plots and at each of the four femalemajority plots. Roots were collected in the field as described, brought back to Portland State University where they were stored at $4{ }^{\circ} \mathrm{C}$ for mycorrhizal analysis (see later). A second collection was made again at these permanent plots on 21 August, when females had set seeds and both males and females had finished flowering.

Roots were taken from storage at $4^{\circ} \mathrm{C}$ and washed with tap water. All collected roots within a sample were stained with Trypan blue, following Koske and Gemma (1989). After staining, fifty 1-cm root segments from each plant were randomly chosen and mounted on slides. AMF colonization was quantified using the magnified intersection method of McGonigle et al. (1990) and examined at 400x. Following Treseder and Vitousek (2001), we report our results as the percentage of examined root length with mycorrhizal structures.

\section{Soil samples 2008}

In October 2008, to determine how majority-female and majority-male sites different in soil nutrient availability; we collected soil from sites at the Sand Lake estuary. 
Six sites were determined, three in female-majority areas and three in male-majority areas; these sites were a random subset of the sites used in the mycorrhizal fungi collections in 2008 (described before). Soil was collected at least $1 \mathrm{~m}$ apart at eight locations at each of the six selected sites. Soil was collected from the top $10 \mathrm{~cm}$, the depth at which D. spicata roots are most common (Sargeant et al., 2008). Samples were sent to the Cornell Nutrient Analysis Laboratory at Cornell University, Ithaca, New York, where they were analyzed for $\mathrm{pH}$ as well as suite of available nutrients: $\mathrm{NO}_{3}, \mathrm{~K}, \mathrm{P}, \mathrm{Mg}, \mathrm{CA}, \mathrm{Fe}$, Al, Mn, Zn.

\section{Data analysis}

Field collection of roots 2008 (Arbuscular Mycorrhizal fungi Root Colonization)

For field-collected plants in 2008, we used a nested, mixed-model ANOVA to test how site (random, nested in site sex), site sex (fixed), season (fixed), and the interaction between site sex and season affected the percentage of examined roots that were colonized by AMF in D. spicata plants. We tested this same model using only colonization of arbuscules, rather than all mycorrhizal colonization (hyphae, arbuscules, and vesicles) because arbuscules have been found to have phenologies that do not necessarily match that of general colonization levels in some systems (Mullen and Schmidt, 1993). However, because these results were quantitatively and qualitatively similar to those for total AMF colonization, they were not reported.

\section{Soil samples 2008}

For soil nutrient analyses, we used nested, mixed-model ANOVAs to determine 
whether each soil nutrient was affected by site (random, nested in site majority-sex) and site majority-sex, followed by a Bonferoni correction for multiple analyses.

\section{RESULTS}

Field collection of roots 2008 (Arbuscular Mycorrhizal fungi Root Colonization)

Examined D. spicata roots from majority-female sites had significantly higher AMF colonization than examined D. spicata roots from majority-male sites (Table 2-1), reflecting a similar pattern of sex-specific colonization to that we found in populations in 2007. However, we also found that AMF colonization has a seasonal component in this salt marsh system. Colonization was significantly higher when plants were not flowering than when they had set seed (Figure 2-1). There was no significant interaction between the majority sex of a site and season, suggesting that majority-female sites showed a similar pattern of higher AMF colonization as majority-male sites across seasons (Figure 2-1 B, C).

\section{Soil samples 2008}

At the Sand Lake field site, phosphorus levels were significantly higher in majority-female sites compared with majority-male sites in October during seed set (Figure 2-1 D). Other nutrients tested, however, did not differ significantly between majority sex sites, although the majority of nutrients showed significant effect of sub-site within majority-sex patches $\left(\mathrm{NO}_{3}, \mathrm{Mg}, \mathrm{CA}, \mathrm{Al}, \mathrm{Zn}\right)$. A significant difference for phosphorus between majority-female and majority-male sites was also found for an earlier data set from a D. spicata marsh at Tomales Bay, California (Eppley, 2000), 
although other micronutrients such as $\mathrm{Mg}, \mathrm{Ca}$, and $\mathrm{Zn}$ were higher in majority-female vs. -male sites in the earlier study. However, this previous study did not use the more conservative sub-site sampling protocol used here, which may be why these additional nutrients were found to vary. Nitrogen was not found to be significantly different between majority-female and majority-male sites in either study. In this study we analyzed only $\mathrm{NO}_{3}$ levels, but in the previous study, we analyzed both $\mathrm{NO}_{3}$ and $\mathrm{NH}_{4}$ levels and found that neither differed between majority-male and majority-female sites.

\section{Discussion}

\section{Sex-specific colonization}

Our data from populations in Oregon over two years demonstrate that there are differences in AMF colonization between the examined roots of male and female $D$. spicata plants. Populations showed roughly similar patterns of sex-specific colonization of examined roots (females had AMF colonization significantly higher than males; Figure 2-1), sex-specific differences in colonization were similar from summer to fall in the field, and the differential colonization occurred despite the fact that majority-female and majority-male sites had similar levels of mycorrhizal spores. Differences in the fraction of analyzed roots with mycorrhizal fungi could be due to either differences in the total number of mycorrhizal fungi in plants or differences in the total root length between the sexes. Previous work on D. spicata has found no growth rates differences between the sexes (Eppley, 2001), but no studies have looked specifically at belowground growth with AMF colonization, and we were unable to obtain sufficient AMF colonization in males in 
our greenhouse manipulation experiment to make the comparison. However, both mechanisms-differential AMF colonization and differential root growth between the sexes-have direct implications for inter-sexual competition in the D. spicata system, which has an extreme variation in the within-population sex ratio.

To the best of our knowledge, this study is the first to show that male and female plants are colonized differentially by AMF, although a previous study demonstrated that male and female plants benefited differentially from mycorrhizal infection (Varga and Kytöviita, 2008). There are little data available on whether males and females differentially interact with their potential mutualistic partners in other species with dimorphic sexual systems. Rarely, sex-specific differences may occur in pollinator mutualisms (Hemborg and Bond, 2005), and a sex-specific mutualistic interaction has been found to occur in the hermit crab Pagurus longicarpus in which males interact more frequently than females with the shell epibiont Hydractinia symbiolongicarpus (Bach et al., 2006). In plant systems, much of the research on sex-specific differences has focused on how variation in response to environmental stress will influence population sex ratios and structure (Geber et al., 1999). To a lesser degree, researchers have investigated sexspecific antagonistic interactions within the community (Ågren et al., 1999). However, mutualistic relationships have the potential to play an equal role in shaping community and population structures, and species that show sex-specific effects in interactions with their environments and other community members might also be expected to interact differentially in positive relationships.

\section{Seasonal variation}


In our field data, we found that AMF colonization in Distichlis spicata varies seasonally (Figure 2-1 A). AMF colonization is high early in the growing season, when plants resprout vegetatively after the long winter, and decreases as the season progresses. As with the sex-specific differences, this result could be due to differences in total AMF colonization at the plant level or to differences in root length between the seasons. The pattern we found, however, is similar to that documented in temperate freshwater wetlands (Bohrer et al., 2004), where maximum plant growth occurs in spring/early summer as does maximum AMF colonization, while flowering times for most species is later, and AMF colonization is much reduced by the end of the summer. Other studies, in salt marsh systems also suggest that AMF colonization is highest when vegetative growth rates are high (van Duin et al., 1990; but see Stenlund and Charvat, 1994; Carvalho et al., 2001), which is most likely in early summer in the D. spicata marshes in Oregon.

Perhaps surprisingly, we found that the sex-specific AMF colonization in examined roots of D. spicata was constant from early summer to fall (Figure 2-1 B and C), despite the fact that females had set seed in the second time period. Females are expected to have a higher allocation to sexual reproduction than males by the fall and thus might have been expected to have higher nutrient needs than males, which mycorrhizal fungi, acting as mutualists, might supply. The constant nature of the sex-specific interaction in D. spicata through the summer and early fall suggests that differential sex allocation is not a likely driver of the sex-specific AMF colonization rates we measured. Also, the plants used in our common-garden experiment never reached reproductive maturity and yet had a pattern of sex-specific AMF colonization (male plants were 
significantly less likely to be colonized than were female plants), adding weight to the suggestion that patterns of sexual allocation are not driving sex-specific AMF colonization variation in this system.

\section{Potential ecological and evolutionary consequences}

Inter-sexual competition in D. spicata is likely influenced by the sex-specific symbiosis with mycorrhizal fungi because differential mycorrhizal colonization in males and females may lead the sexes to have differential access to resources. Mycorrhizal relationships have been proposed to change competitive plant interactions by either (1) increasing competition because individuals have greater access to scarce resources (Facelli et al., 1999) or (2) decreasing competition because limited resources are shared via a hyphal network (Shumway and Koide, 1995). Empirical results suggest that AMF colonizations are likely to exacerbate competitive interactions, rather than reduce them (Allsopp and Stock, 1992; Shumway and Koide, 1995; Facelli et al., 1999). Thus, we expect that the sex-specific interaction with mycorrhizal fungi and $D$. spicata magnifies differential competitive effects between males and females, intensifying inter-sexual competition. Because mycorrhizal interactions also increase size inequalities among plants within species (Moora and Zobel, 1998), any advantage that AMF colonization may confer to one sex is likely to be increased in inter-sexual competition but not in intrasexual competition.

Inter-sexual competition has been implicated as one probable mechanism responsible for the spatial segregation of the sexes in D. spicata populations where higher 
nutrient sites have nearly $100 \%$ female majorities and lower nutrient sites have nearly 100\% male majorities (Eppley et al., 1998; Eppley, 2000, 2006). Determining the mechanisms responsible for spatial segregation of the sexes in plants is important for understanding dioecious plant population biology, as the pattern has been documented in over 25 plant species from 18 families (Bierzychudek and Eckhart, 1988; Iglesias and Bell, 1989; Korpelainen, 1991; Shea et al., 1993; Lokker et al., 1994; Eppley et al., 1998; Bertiller et al., 2002; Stark et al., 2005; Dudley, 2006). One potential mechanism responsible for spatial segregation of the sexes in D. spicata is inter-sexual competition, such that female plants may outcompete male plants for high phosphorus sites in the marsh, because phosphorus is the one nutrient we found to differ between female- and male-majority sites. Preferential interactions with mycorrhizal fungi for female plants over male plants may expedite this outcome. While typically mycorrhizal fungi react negatively to high rates of nutrients (Treseder, 2004), our results from the field site at Salt Lake, Oregon and those taken previously in California (Eppley, 2005) suggest that even majority-female sites in the D. spicata salt marsh have low levels of phosphorus and are nutrient limited. Whether majority-female sites are phosphorus limited and mycorrhizal fungi play a role in inter-sexual competition remains to be seen. Why males do not benefit equally from a similar high level of mycorrhizal interaction and establishment in relatively higher-nutrient sites also remains unclear. Females may have higher resource needs than males due to the presumably higher costs they pay for sexual reproduction (due to the high costs of maturing fruit), which may mean that they benefit more from high rates of AMF colonization than do males. Further manipulative experiments, which we are pursuing, are needed to determine how the sex-specific relationship between 
mycorrhizal fungi and $D$. spicata influences inter-sexual competition above and

belowground and the sex ratios in this system. Investigations are also needed into how the interaction between sex allocation and phosphorus influences AMF colonization in $D$.

spicata. 
Table 2-1. Results of nested, mixed-model ANOVA to test how site (random, nested in site sex), site sex (fixed), and season (fixed) affected colonization by AMF in D. spicata plants collected from the field in 2008. Significant $P$-values are in boldface.

Source of variation

Site (site sex)

Site sex

Season

Site sex $\mathrm{x}$ season

Error df

6

1

1

1

118
F

$P$

\begin{tabular}{cc}
1.68 & 0.13 \\
33.95 & $\mathbf{0 . 0 0 1 1}$ \\
15.14 & $\mathbf{0 . 0 0 0 2}$ \\
0.11 & 0.74 \\
\hline
\end{tabular}

0.0011

0.0002

0.74 
Figure 2-1. Percentage of analyzed root colonized by AMF $(+$ SE) in Distichlis spicata plants at Sand Lake, Oregon in (A) all sites for the 2 July 2008 collections when plants were green but not reproductive vs. the 21 August 2008 collections when females were setting seed $(N=128)$; (B) majority-female vs. majority-male sites for 2 July $(N=128)$; and (C) majority-female vs. majority-male sites for 21 August $(N=128)$. (D) Soil phosphorus levels (ppm) at majority-female and majority-male sites $(+\mathrm{SE})$ for 21 August $2008(N=48)$. 
Figure 2-1
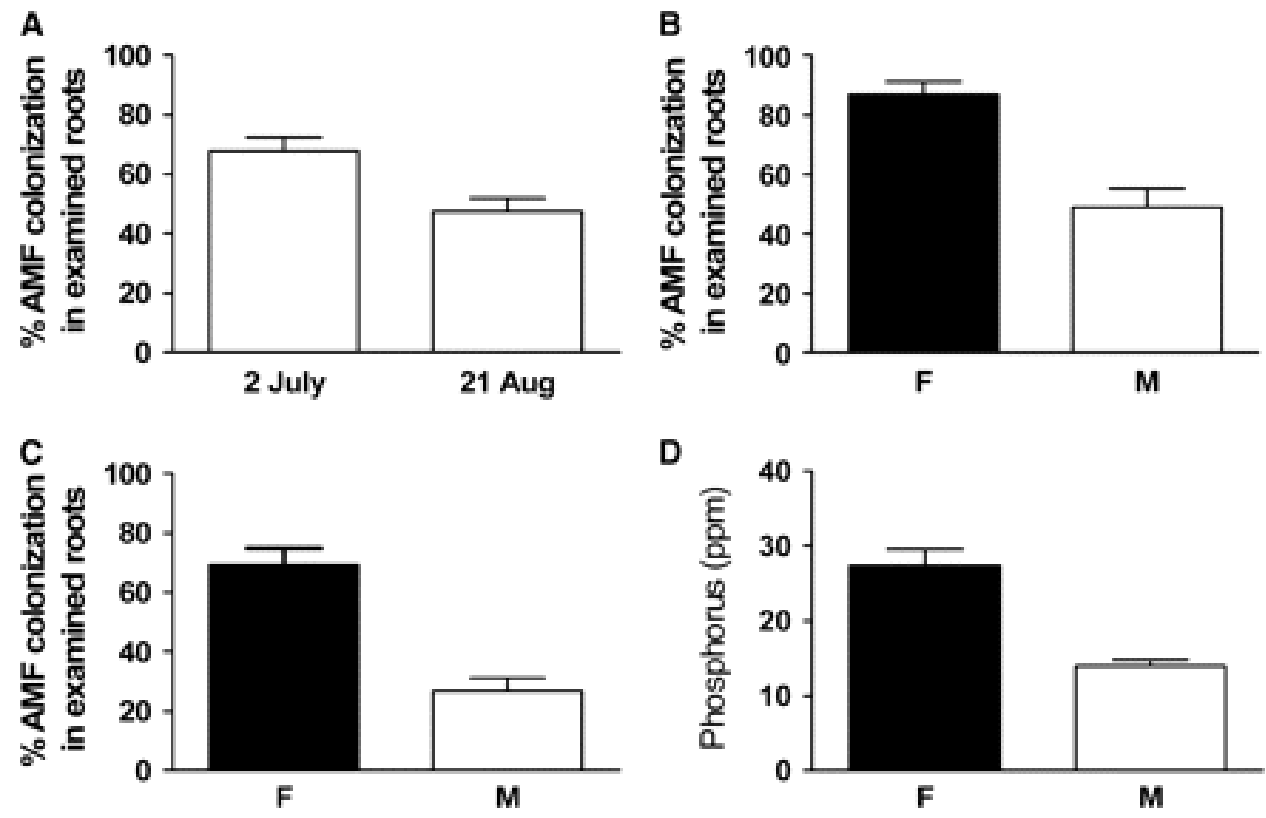


\title{
Chapter 3: Inter-sexual competition in a dioecious grass
}

\begin{abstract}
Spatial segregation of the sexes (SSS) occurs in many dioecious angiosperms, but little data are available on the fitness advantages, if any, for males and females. We examined whether reciprocally transplanted male and female seedlings of Distichlis spicata, a dioecious grass species that exhibits extreme SSS differed in their responses to microhabitats and competition treatments. Plants grown without conspecific competitors grew equally well in both male- or female-majority habitats, suggesting that male and female plants do not have differential resource needs at the juvenile life-history stage. However, plants subject to intra-sexual competition were significantly larger than plants subject to inter-sexual competition, suggesting that niche partitioning may occur in $D$. spicata.
\end{abstract}

Keywords: Dioecy $\cdot$ Distichlis spicata $\cdot$ Niche partitioning $\cdot$ Sex ratio $\cdot$ Sexual system Introduction

In many animal and plant species with separate sexes, population sex ratios are significantly biased (for review Hardy 2002), although 1:1 sex ratios are more common for most species (Rottenberg 1998). Biased adult sex ratios may be a product of biased primary sex ratios, which are predicted to evolve if the costs of producing male and female offspring are unequal (Fisher 1930), or due to additional selection factors such as local mate competition (LMC; Hamilton 1967). Regardless of the primary sex ratio, biased adult sex ratios may arise due to differential mortality of males and females during any life-history stage. Sex ratio research has held a central place in the study of life- 
history evolution because the theory is well-developed and thus theoretical predictions and empirical data are expected to agree (West et al. 2002). Thus, while variation in sex ratios may not be the norm within or among populations, the occurrence of such wide sex ratio variation in some species allows us to test our understanding of sex ratio theory and the role of selection in maintaining stable sex ratios.

One of the most extreme forms of sex ratio bias that is commonly found in dioecious plants is within-population sex ratio variation along an environmental gradient — a pattern known as "spatial segregation of the sexes" (SSS; (Bierzychudek and Eckhart 1988a)). Little is known about mechanisms responsible for this pattern, although spatial segregation of the sexes is widespread, occurring in over 30 species from 20 families ((Bertiller et al. 2002a; Bertness et al. 1987; Bierzychudek and Eckhart 1988a; Dudley 2006; Eppley et al. 1998b; Iglesias and Bell 1989; Korpelainen 1991; Lokker et al. 1994a; Shea et al. 1993; Stark et al. 2005) Spatial segregation of males and females is surprising in sessile organisms because an increase in distance between the sexes should reduce fertilization success and presumably the fitness of each individual (e.g., (Bawa and Opler 1977b; Brazeau and Lasker 1992; Burczyk et al. 1996; Levitan et al. 1992)

Two mechanisms have been proposed previously for the evolution of SSS in dioecious plants (for review (Bierzychudek and Eckhart 1988a). One explanation suggests that plants have evolved to occupy different niches because inter-sexual competition is greater than intra-sexual competition (niche partitioning). If inter-sexual competition decreases plant fitness more than intra-sexual competition in a species with SSS then niche partitioning may be occurring. Alternatively, differences in reproductive 
morphology between the sexes may cause males and females of the same species to become specialized to different habitats and thus evolve different niches (sexual specialization). If fitness is higher for females in female-majority habitat and for males in male-majority habitat then sexual specialization is a likely mechanism for SSS in that species. These two proposed hypotheses are not mutually exclusive, and there is the ability for a combination of niche partitioning and sexual specialization within the same species. We are aware of no studies that have tested differences in inter- versus intrasexual competition in plants, and thus little is known about the possibility of niche partitioning in plants. In plant species with genetic sex determination, only two studies have examined sex-specific competitive abilities ( $\mathrm{gren}$ et al. 1999 for review; Conn and Blum 1981; Lovett-Doust et al. 1987). Both studies showed that females are competitively superior to males in terms of growth and survival at high densities. Similarly, in dioecious plant species with genetic sex determination, males and females respond differently to variable resource availability (Correia and Díaz Barradas 2000); e.g.,(Dawson and Bliss 1989); Dawson and Ehleringer 1993; (Li et al. 2004; Verdu et al. 2004); Verdu et al. 2004); however, no studies have demonstrated sexual specialization in a dioecious species, by showing that males and females are more fit in different microhabitats. To demonstrate sexual specialization and to determine whether its cause is differential resource needs between the sexes, reciprocal transplant experiments are needed, with plants grown with and without inter-sexual competition. Thus, in plant species exhibiting SSS, little data are available to suggest whether niche partitioning and sexual specialization are likely mechanisms explaining SSS.

In this study, we used a reciprocal transplant experiment to test niche partitioning 44 
and sexual specialization as potential mechanisms responsible for SSS in the dioecious, long-lived salt marsh grass Distichlis spicata (Poaceae). D. spicata exhibits a striking pattern of spatial segregation of male and female genotypes, in which within-population sex ratios spatially vary from nearly $100 \%$ male to nearly $100 \%$ female (Bertness et al. 1987), (Eppley et al. 1998b). Using a RAPD-PCR marker co-segregating with the female phenotype, Eppley et al. (1998) showed that sex is genetically determined in D. spicata, and this species exhibits spatial segregation of male and female genets (genetic individuals), rather than segregation of ramets or flowering potential. Subsequent work showed that sites with female majorities of $D$. spicata are at slightly lower elevations in the salt marsh than sites with male majorities (Eppley 2001) and that majority-female sites are higher in phosphorous than are majority-male sites (Eppley et al. 2009a). This earlier work also showed that seed germination and seedling mortality are affected by sex-by-environment interactions (Eppley 2001) and that male and female D. spicata plants have differential competitive effects during intraspecific competition (Eppley 2006)) Here, to determine the extent to which SSS in D. spicata is caused by niche partitioning and/or sexual specialization, we used a reciprocal transplant experiment in the field-without competition and with intra- versus inter-sexual competition. We measured survival, dry weight (as measures of fitness), and root/shoot ratio (as a measure of competitive interactions) of transplants after 15 months.

\section{Materials and Methods}

The study system 
Distichlis spicata (Poaceae) is a dioecious, perennial grass that is common in salt marshes on the east and west coasts of North America (Hitchcock 1971). In the western United States, D. spicata occupies middle and upper reaches of salt marshes, occurring at high densities with species such as Salicornia virginica, Triglochin maritima, and Plantago maritima (Mcdonald and Barbour 1974; Watson and Byrne 2009). Sexual reproduction in D. spicata involves wind dispersal of pollen (Beetle 1943); (Hitchcock 1971)) and water and bird dispersal of seeds (personal observations, S. Eppley), with extensive asexual propagation by rhizomes (Beetle 1943); (Hitchcock 1971). Plants reach sexual maturity within 10 months in growth chambers (Eppley et al. 1998b); however, rates of sexual maturity under field conditions have not been reported, as far as we are aware.

We conducted the fieldwork for this study in populations of Distichlis spicata at the Sand Lake and Whalen Island salt marshes, Tillamook County, Oregon. In previous work in these Oregon marshes, we determined that the plants exhibited spatial segregation of the sexes (Eppley et al. 2009a). In this previous study, we found that around a randomly-selected female D. spicata plant, the mean sex ratio (proportion of male individuals) was $0.32 \pm 0.05$ (SE), while around a randomly-selected male $D$. spicata plant, the sex ratio was $0.73 \pm 0.04$ (SE). Field sites were located in the mid-tidal height region of the salt marshes, and the sites were inundated frequently (daily to weekly depending on season and location within the marsh), with majority-female sites receiving more inundations, on average, than majority-male sites, as they are generally lower in the marsh (Eppley 2001).

Reciprocal transplant of seedlings in the field 
To compare the effects of potential variation between majority-female and -male sites on growth and flowering of male and female seedlings of $D$. spicata plants, we conducted a reciprocal transplant of male and female ramets into majority-male and female sites in the two populations. We grew $D$. spicata in the greenhouse from native seeds collected from the sites in 2008. Germination of seedlings began in early March. We prepared seeds for germination by rinsing them in a $\sim 5 \%$ bleach solution and in deionized water. The seeds were placed onto filter paper in plastic Petri dishes with 20 seeds per Petri dish. In total, we had 47 Petri dishes with 940 seeds. To prevent fungal contamination during germination, we submerged the seeds into a fungicide solution $(0.26 \mathrm{~g} / \mathrm{l}$ of Bonide Captan 50\% WP in deionized water).

Once seeds germinated (408 seedlings produced from 940 seeds), they were planted into Cone-tainers (Ray Leach Cone-Tainer Nursery, Canby, Oregon, USA), with 30 holes ( $7.9 \mathrm{~mm}$ width) drilled into each cone to allow plants access to water and dissolved nutrients from soil in the surrounding environment, once cones were transplanted into the salt marsh environment. Plants remained in the cones after transplant to allow us to restrict competition to the assigned treatments (some plants with no competition, some plants with one competitor) within the dense salt marshes. Cones contained loose cotton fabric to ensure roots would not easily escape through the holes (or rhizomes from other plants would enter) and a cotton ball was placed at the bottom to provide soil stability. The soil used in the cones was a mixture of 1 part Black Gold ${ }^{\circledR}$ “All Organic" potting soil (Sun Grow Horticulture, Vancouver, Canada) to 3 parts propagation sand. We chose to use this low-nutrient greenhouse soil mixture, rather than field-collected soil, as field-collected soil is interspersed with rhizomes of D. spicata. 
Removing or killing rhizomes was intractable for this size experiment, and we felt that plants would experience sufficient effects of their transplant environments during the exchange of water and nutrients from surrounding soil as water permeated cones via the drilled holes. Seedlings were planted into cones either singly (no competition) or in pairs (inter- and intra-sexual competition), and allowed to establish in the greenhouse for three months. Previous work with D. spicata found that young seedlings suffered $100 \%$ mortality in a few weeks (Eppley 2001), and thus we waited to transplant until seedlings were slightly more established. During the greenhouse establishment phase, 42 seedlings died and were removed from the experiment, which left us with 366 seedlings in 239 cones (112 cones with single seedlings and 127 cones with pairs of seedlings). When the seedlings were placed in the cones, the sex of the plants was unknown.

In early June 2008, when native D. spicata had become green in the salt marsh, cones were planted into each of the two populations in Tillamook County, Oregon. We established twelve 2-x-2 m blocks: three in majority-female sites within the Sand Lake marsh, three in majority-male sites within the Sand Lake marsh, three in majority-female sites within the Whalen Island marsh, and three in majority-male sites within the Whalen Island marsh. The 366 plants in 239 cones were randomly planted into these blocks in sets of 20 or 21 .

To determine the sex of the 366 seedlings, we used sex-specific molecular markers. Leaves were taken from each plant relative to the size of the plant (approximately $5-\mathrm{x}-1 \mathrm{~cm}$ ) and dried on silica gel. The plant samples were frozen at $4{ }^{\circ} \mathrm{C}$. We extracted DNA using the DNeasy Plant Mini Kit (Qiagen, Valencia, California) and followed the plant mini extraction protocol. The sex of each plant was determined using a 
set of D. spicata sex-specific STS markers, following Eppley et al. (2009). Sex was determined only if a 1062 bp control band was present and was considered female if there was a $317 \mathrm{bp}$ band and male if no $317 \mathrm{bp}$ band was present. Three of the 366 seedlings could not be sexed because of insufficient tissue for DNA extraction and were removed from the experiment. One additional seedling was removed from the experiment because its competitor plant was one of the seedlings that could not be sexed. Once the sexes of the 362 remaining transplanted seedlings were known, we determined that we had 237 cones with plants of known sex, including 112 cones with single seedlings (46 cones with single male plants and 66 cones with single female plants) and 125 cones with pairs of seedlings ( 26 cones with pairs of male plants, 41 cones with pairs of female plants, and 58 cones with a male and a female plant). The number of cones of each competition treatment was not equal because plants were established in cones as seedlings before their sex was determined (see above).

All cones were pulled from the field on August 31, 2009, after 15 months and survival was assessed. One hundred and thirty-two plants (of the original 366 seedlings transplanted) survived to harvest and were dried at $60^{\circ} \mathrm{C}$ for 7 days in a drying oven. We determined the dry weight of plants on a Mettler Toledo AB54-S/Fact balance, with separate measures for roots (roots and rhizomes) and shoots (all tillers).

\section{Data analysis}

We used a nominal logistic model (SAS Institute 2007) to analyze how competition type (inter-sexual, intra-sexual, and no competition), plant sex (male or female), site majority-sex (male or female), population, block (nested in population and 
site majority-sex), and interactions among these factors affected survival of each plant. We used mixed-model, nested ANOVAs (SAS Institute 2007) to analyze how competition type (a fixed effect), plant sex (a fixed effect), site majority-sex (a fixed effect), population (a random effect), block (a random effect, nested in population and site majority-sex), and interactions among these factors affected 1) the dry weight and 2) root/shoot ratio of each plant. For pots with two competing plants, one plant was randomly chosen for these analyses. Root/shoot data were inverse transformed to meet the assumptions of the ANOVA model. Non-significant interactions were dropped from the models. In the ANOVA analyses, the residuals were normally distributed, and variances were homogeneous. For the ANOVAs, if a significant difference was found for a particular factor, we used post-hoc analyses (Tukeys tests) to determine which means were significantly different. Bonferonii corrections were used to correct for multiple tests (dry weight and root/shoot ratio) on the same individual transplants, and results are shown only for P-values after the correction. If a seedling in a competition pair died or washed away while the transplant cone was in the field, the surviving seedling was retained in the competition treatment, rather than being reassigned to the non-competition treatment, as the seedling was under competition for at least the establishment life-history stage. For seedlings in competition that survived and were analyzed for dry weight and root/shoot ratio, $82.7 \%$ retained their competitive partner until the end of the experiment. We re-analyzed the data for dry weight and root/shoot ratio without these plants using the same ANOVA models, and their inclusion did not change the overall significance of any factors in these models. 


\section{RESULTS}

Survival

For the 15 month experiment, $33.47 \%$ of transplants survived. Of the plants that died, $99.6 \%$ were gone from the planting site by the end of the experiment; only a handful of plants died and remained in place. Competition type did not have a significant effect on survival; plants with no competition, with intra-sexual competition, and with inter-sexual competition survived at the same frequency (Table 3-1). Plant sex also did not have a significant effect on transplant survival; both male and female plants survived at the same frequency. Site majority-sex had a significant effect on transplant survival. Plants survived at a greater rate in majority-male sites compared with majority-female sites (mean survival \pm se; $42.19 \pm 7.21 \%$ and $22.31 \pm 8.55 \%$, respectively). Population was a significant factor in transplant survival, with plants surviving at a greater rate in the Whalen Island population than in Sand Lake population (mean survival \pm se; $43.62 \pm$ $9.52 \%$ and $21.99 \pm 6.61 \%$, respectively). There was also a significant interaction between population and site majority-sex; for the Sand Lake population, there was a greater differential between survival in male- and female-majority sites than occurred in the Whalen Island population. Block was a significant factor in plant survival (as it was for all subsequent analyses), suggesting significant environmental variation within populations. The sex of the plants and competition type were not significant with respect to survival in this transplant experiment. Interactions, including the potentially interesting interaction between the sex of the plants and site majority-sex, were not significant.

Dry weight 
Competition type did have a significant effect on dry weight (Table 3-2; Figure 31). Post-hoc analysis suggests that plants subject to intra-sexual competition were substantially larger than plants subject to either inter-sexual competition or no competition, while the inter-sexual competition and no competition treatment were not significantly different from one another. Plants under intra-sexual competition were more than 2.5 times larger than those under inter-sexual competition. Population was not significant with respect to dry weight, as transplants in both populations showed the same patterns. Block was significant and plant sex was marginally significant $(P=0.10$; mean dry weight $\pm \mathrm{se} ; 0.09 \pm 0.02 \mathrm{~g}$ and $0.07 \pm 0.01 \mathrm{~g}$, for males and females respectively). Site majority-sex and all interactions were not significant factors with respect to dry weight.

Root/shoot ratio

Competition type also had a significant effect on root/shoot ratio (Table 3-2;

Figure 3-2). Plants growing with an inter-sexual competitor had a significantly larger root/shoot ratio than plants growing alone. Plants with an intra-sexual competitor could not be distinguished in root/shoot ratio from either other competition types. Population, block, plant sex, site majority-sex, and all interactions were not significant with respect to root/shoot ratio.

\section{Discussion}

Niche partitioning

The results of this study demonstrate that plants can respond differentially to intra-versus inter-sexual competition from conspecifics. We found that plants growing 
with inter-sexual competitors had substantially less biomass than plants growing with intra-sexual competitors (Figure 3-1), lending support for the niche partitioning hypothesis proposed to explain spatial segregation of the sexes in dioecious plants. Selection could favor traits that minimize competition between the sexes, and thus result in spatial segregation of males and females. This type of selection would be favored if competition between males and females was greater than competition between plants of the same sex (Bierzychudek and Eckhart 1988a)), as our data indicates may occur in $D$. spicata. However, previous research in dioecious plants suggests that intra-sexual competition is likely to be more severe than inter-sexual competition (Putwain and Harper 1972; Wade 1981). It should be noted that only one of the three species examined in these studies showed population sex ratio variation and none exhibited SSS. Furthermore, more recent studies suggest that competition by plant roots may be highest among genotypes with greater differences and least among similar genotypes due to species recognition, kin recognition, and self/non-self recognition ((Biedrzycki et al. 2009); (Dudley and File 2007; Falik et al. 2003; Gruntman and Novoplansky 2004; Mahall and Callaway 1991); Mahall and Callaway 1996; Semchenko et al. 2007). If this pattern holds for competition among sexual morphs, then competition between males and females may be greater in some species than competition between same sex plants either because 1) plants cannot distinguish between the opposite sex and more distant genotypes with which they compete or more likely 2) plants use a similar system of recognition (such as employed for kin recognition) to determine inter- versus intra-sexual competition. A system of inter- versus intra-sexual recognition could be favored in a species if plants had higher fitness in competition with their own sex than with the 
opposite sex, and seed dispersal was relatively random, such that competition among siblings was limited (reducing the negative fitness effects for mothers passing the trait on to their offspring).

Inter-sexual competition also appeared to have an effect on root/shoot ratios. Our results suggest that plants subject to inter-sexual competitors have larger than average root/shoot ratios compared with plants subject to no competition (Figure 3-2), and this is not unexpected as belowground allocation is typical for plants in competition (Gersani et al. 2001). However, plants in the competition treatments were grown with two plants per cone, while plants in the treatment with no competition were grown with only one plant per cone, allowing half the rooting volume for plants in the competition treatments as those in the treatment without competition. Previous studies have found that, independent of competition, belowground biomass is positively correlated with rooting volume in plants ((Hess and De Kroon 2007; McConnaughay and Bazzaz 1991). Thus, the difference in root/shoot ratio we found between plants in inter-sexual competition (with half the rooting volume) and those with no competition suggests that the belowground competition between male and female plants was strong to overcome differences in rooting volume. Strong belowground competition in D. spicata is not unexpected, as these plants are growing in nutrient-poor soils (Kiehl et al. 1997; Ngai and Jefferies 2004; Tyler 1967; Valiela and Teal 1974), and research has shown that in resource-poor habitats a higher proportion of biomass will be concentrated in plant roots (Casper and Jackson 1997). The belowground competition between inter-sexual competitors may be mediated by plant exudates, such as phenols, flavonoids, amino acids, and proteins, which are known to mediate plant-microbe interactions (Bais et al. 2006). What is unexpected is 
that plants without competition, despite having a smaller root/shoot ratio (and thus potentially more photosynthetic tissue) and no competitor, are not larger than plants with inter-sexual competitors. Perhaps, more time was needed for dry mass differences to accrue between these treatments, or as nutrients are limiting this system, perhaps allocation to belowground biomass allows more biomass accumulation than does allocation to aboveground biomass.

Plants subject to intra-sexual competition were not significantly different in root/shoot ratio than plants in either other treatment, but the mean for this treatment was much closer to those for plants without competition than for those plants with intersexual competition (Figure 3-2). However, though plants with intra-sexual competitors had roughly the same size root/shoot ratio as plants without competitors, they had much larger biomass (Figure 3-1). How plants with intra-sexual competitors could have increased their biomass above that of plants with no competitors remains an open question. Possible explanations include: 1) the sample size for plants without competition was low, and thus the mean biomass for this treatment was not accurate or 2) the lack of belowground competition for intra-sexual competitors forced the plants to compete for light. A previous study found that when plants compete for light in heterogeneous light environments, as is the case for D. spicata, plants subject to competition show the same or even larger biomass compared to plants grown without competitors (Huante et al. 1998). Future work in D. spicata will be needed to parse out the importance of aboveand belowground competition to the inter- versus intra-sexual competition treatments, and follow plants through to reproductive maturity, as our experiment was restricted to the early life history stages. More research is also needed to determine whether greater 
belowground competition between males and females rather than between same sex $D$. spicata individuals may explain the differences for dry weight between inter- and intrasexual competition. With this aim, we are initiating lab experiments following protocols in Biedrzycki (2010) in which we grow seedlings with root exudates from seeds of known sexes.

The data on survival of transplants in the field do not support the niche partitioning hypothesis. Survival of seedlings was not affected by plant sex or competition treatments that we imposed on transplanted seedlings, as would be expected if niche partitioning were affecting survival. However, plants survived at significantly higher rates in majority-male sites compared with majority-female sites, which may reflect the more frequent inundation in the lower elevation female-majority sites compared with higher elevation majority-male sites. A previous reciprocal transplant study of $D$. spicata seedlings did not find a survival differences between majority-sex sites in a California marsh, but the experiment was for a much shorter time period (Eppley 2001). This differential effect in survival between majority-sex sites was greater in the Sand Lake population than in the Whalen Island population, which is not unexpected as Whalen Island has a levy protecting majority-female sites from winter storms, while Sand Lake is more exposed to tidal inundation.

\section{Sexual specialization}

If sexual specialization, such as physiological differences between the sexes were responsible for SSS, we would expect that fitness was higher for females in femalemajority sites and males in male majority-sites (Bierzychudek and Eckhart 1988a). Thus, 
if sexual specialization had been selected in D. spicata, we would expect to see a significant interaction in our results between plant sex and site majority-sex (if plants in all competition treatments showed the pattern) or a significant three-way interactions between plant sex, site majority-sex, and competition treatment (if plants in only a subset of competition treatments showed the pattern, such as plants without competitors) for transplant survival or dry weight. However, we found that plant sex was not significant in any two-way or three-way interactions for any of our measures (survival, dry weight or root/shoot ratio). Also, we analyzed our data with only the transplants without competitors, and confirmed that the interaction between plant sex and site majority-sex was not significant (results not shown). These results suggest that sexual specialization is not occurring and is a not a selective force for SSS in juveniles.

However, by the end of the experiment, our sample size for transplants without competitors was exceptionally small as many plants died during the 15 month transplant period, and a previous study in D. spicata found evidence of specialization using younger seedlings (Eppley 2001), with higher female survival than male survival in femalemajority sites. Furthermore, our experiment only examined plants in the first few months of their lifespan, and did not allow transplants to reach sexual maturity. Sex-specific physiological differences between the sexes is most likely to occur during the reproductive stage when males and females are morphologically most distinct (Delph et al. 1996), so sexual specialization should not be ruled out as a selective force overall for this species.

\section{Conclusion}


Our data suggest that niche partitioning plays a role in SSS in Distichlis spicata, with inter-sexual competition greater than intra-sexual competition at the seedling stage. Also, our experiment did not demonstrate any evidence of sexual specialization in $D$. spicata. However, sexual specialization cannot be ruled out as a mechanism responsible for SSS in D. spicata, as our sample size for detecting its effects was low. Moreover, plants did not reach sexual maturity, a factor which is likely to influence effects both on sexual specialization and niche partitioning. Sexual maturity is expected to change sexspecific resource demands and thus change both competitive abilities as well as relative male and female fitness in a given environment. To resolve the relative importance of niche partitioning and sexual specialization in explaining SSS in this species, future studies should include reciprocal transplants throughout flowering and seed set. Currently we have long-term, reciprocal transplants in place to further address the roles of sexual specialization and niche partitioning in D. spicata.

\section{Acknowledgements}

The authors thank A. Bonham, A. Brown, C. Haaning, S. Rogers, and E. Shortlidge for research help and anonymous reviewers for comments on the manuscript. Research was supported by Portland State University and the National Science Foundation (DEB 0743461). The study was conducted in accordance with current U.S. laws. 
Table 3-1 Logistic model used to determine the effects of competition type (inter-sexual, intra-sexual, and no competition), plant sex, site majority-sex, population, block (nested in population and site majority-sex), and interactions between these factors on survival of Distichlis spicata transplants after 15 months in the field. Non-significant interactions are not shown; see Data analysis section for details. $n=237$

\begin{tabular}{llll}
\hline Source & $\boldsymbol{d} \boldsymbol{f}$ & Chi-square & $\boldsymbol{P}$ \\
\hline \hline Competition type & 2 & 4.05 & 0.13 \\
\hline \hline Plant sex & 1 & 0.99 & 0.32 \\
\hline \hline Site majority-sex & 1 & 15.44 & $<\mathbf{0 . 0 0 0 1}$ \\
\hline \hline Population & & & 14.91 \\
\hline \hline Block (population, site majority-sex) & 8 & 23.33 & $\mathbf{< 0 . 0 0 0 1}$ \\
\hline \hline Population $\times$ site majority-sex & 1 & 6.37 & $\mathbf{0 . 0 0 3}$ \\
\hline
\end{tabular}


Table 3-2 ANOVAs were used to determine the effects of competition type (a fixed effect; inter-sexual, intra-sexual, and no competition), plant sex (a fixed effect), site majority-sex (a fixed effect), population (a random effect), block (a random effect; nested in population and site majority-sex) on A) dry weight and B) root/shoot ratio of transplants after 15 months in the field. Pvalues in bold are significant after the Bonferroni correction.

\begin{tabular}{lcccccccc} 
& \multicolumn{3}{c}{ A. Dry Weight } & \multicolumn{5}{c}{ B. Root/Shoot Ratio } \\
Source & df & MS & F & P & MS & F & P \\
\hline Competition Type & 2 & 0.03 & 9.56 & $\mathbf{0 . 0 0 0 2}$ & 0.35 & 5.77 & $\mathbf{0 . 0 0 5}$ \\
Plant Sex & 1 & 0.01 & 2.90 & 0.10 & 0.00 & 0.00 & 0.97 \\
Site Majority-Sex & 1 & 0.00 & 0.02 & 0.90 & 0.16 & 1.33 & 0.28 \\
Population & 1 & 0.01 & 1.24 & 0.30 & 0.57 & 4.47 & 0.70 \\
Block (Population, Site Majority-Sex) & 7 & 0.01 & 3.16 & $\mathbf{0 . 0 0 6}$ & 0.15 & 2.40 & 0.03 \\
Error & 65 & 0.00 & & & 0.06 & & \\
\hline
\end{tabular}


Figure 3-1 Dry weight (mean $\pm \mathrm{SE}$ ), $n=78$, of Distichlis spicata transplants after 15 months in the field, grown in three competition treatments: None no competitor, Inter an inter-sexual competitor of the same species, or Intra an intra-sexual competitor of the same species. Different letters indicate significant differences $(P<0.05)$ among treatments

Figure 3-2 Root/shoot ratio (mean $\pm \mathrm{SE}$ ), $n=78$, of Distichlis spicata transplants after 15 months in the field, grown in three competition treatments: None no competitor, Inter an inter-sexual competitor of the same species, or Intra an intra-sexual competitor of the same species. Different letters indicate significant differences $(P<0.05)$ among treatments. 
Figure 3-1

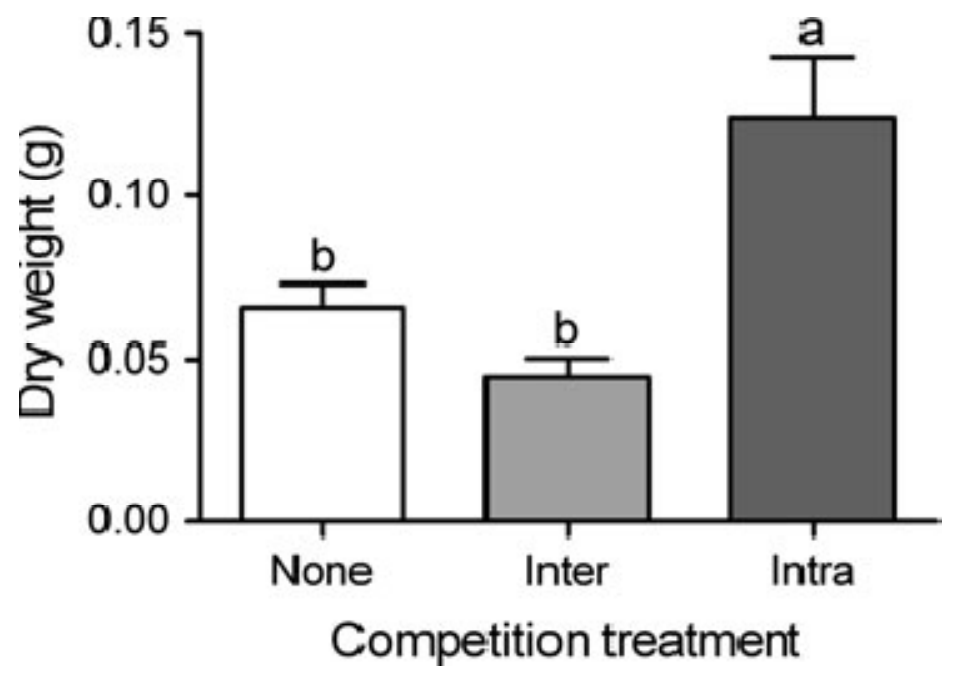


Figure 3-2

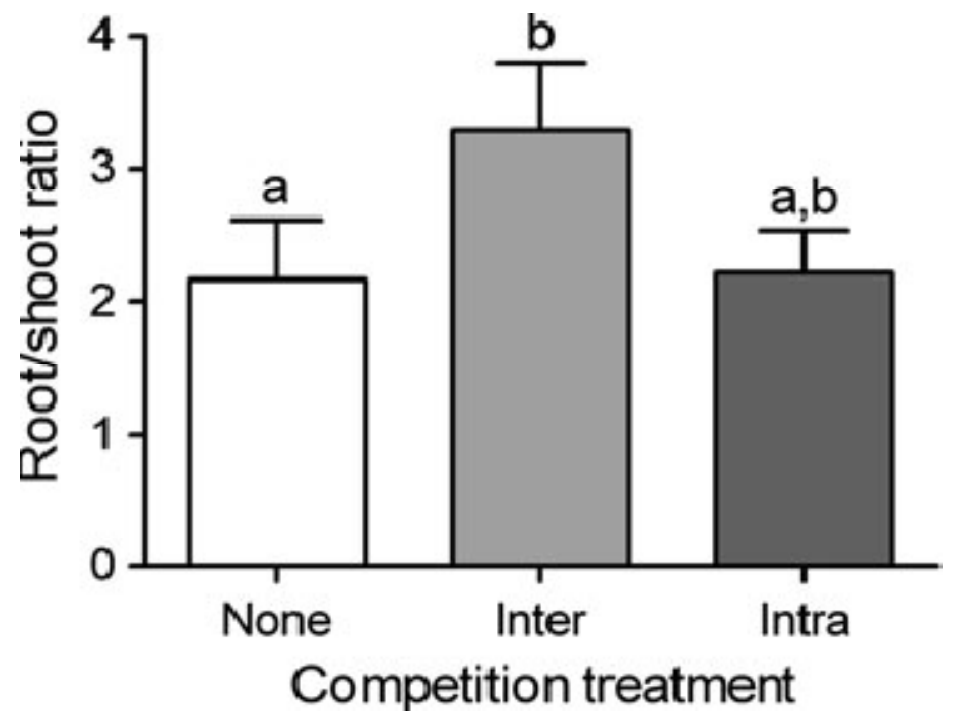




\title{
Chapter 4: Kin recognition and inter-sexual competition in a dioecious grass
}

\begin{abstract}
Plants have evolved complex mechanisms to recognize and respond to the presence of a neighbor. Recent studies on root identity have found that roots are able to differentiate among neighboring roots based on whether the neighbor is self/non-self or kin/stranger. Similar to results found in animals, plants show species-specific responses to self/nonself and kin/stranger recognition. We use the species Distichlis spicata, a perennial, dioecious, monocot with separate plants occupying areas with nearly $100 \%$ male and nearly $100 \%$ female (spatial segregation of the sexes, SSS). The purpose of our experiment was to examine the response of $D$. spicata roots when exposed to liquid media (addition of root exudates and/ or subtraction of nutrients) previously occupied by another plant. We address the following questions: (1) Do D. spicata plants show plasticity in their root response depending on if the other plant is a kin or a stranger? (2) Do D. spicata plants show plasticity in their root response depending on if the other plant is an intra-sexual or inter-sexual competitor? We found that plants paired with another KIN had significantly greater number of lateral roots and root length. Also, plants subject to inter-sexual competition were significantly smaller and had a greater root/shoot ratio than plants subject to intra-sexual competition. These findings suggest that D. spicata can recognize differences in relatedness and sexual competitors due changes in the environment that occur; either due to plants adding exudates to the media and/or by removing nutrients.
\end{abstract}


Keywords kin recognition, dioecy, competition, root-root interactions, inter-sexual competition

\section{Introduction}

The ability for a plant to recognize another plant in the surrounding rhizosphere as either self/ non-self or kin/stranger has important implications for behavioral, ecological and evolutionary processes (Callaway and Mahall 2007). Plants have been shown to be phenotypically plastic in response to the cues and signals they receive from competitors, changes in resource availability and changes in space (Murphy and Dudley 2009; Hodge 2004; Hodge 2006; Valladares et al. 2007; Silvertown and Gordon 1989; Novoplansky 2009). When confronted by a neighboring plant, research has demonstrated that plants perceive neighbors aboveground via light fluxes and spectral composition (Novoplansky 2009; Smith 2000; Weinig 2002) and belowground via volatile compounds and root exudates (Mahall and Callaway 1991). Due to the modularity of the root structure, a plant can avoid the neighbor, confront the neighbor or tolerate the neighbor belowground (Novoplansky 2009), and the plant will distribute resources aboveground or belowground accordingly (Hodge 2009). Due to belowground root competition having a greater reduction on plant fitness then aboveground competition (Casper and Jackson 1997; Wilson 1988) and competition overall causing an allocation shift of resources to nonreproductive functions (Novoplansky 1990, Dudley and Schmitt 1996, Weinig 2000, Novoplansky 2003), self/non-self and kin recognition studies emphasizing the effects roots have on one another are an important step in determining the effects of competition versus cooperation in plants. 
Mahall and Callaway $(1991,1992,1996)$, in a self/non-self recognition study, showed that when Ambrosia dumosa roots encountered non-self roots (plant from the same population), root growth was inhibited; however, when roots of clones were encountered roots did not stop growing. This study prompted other studies on self/non-self recognition, and these studies found opposite results; roots avoided competition with other roots from the same plant, in Fragaria chiloensis (Holzapfel and Alpert 2003), Pisum sativum (Falik et al. 2003; Gruntman and Novoplansky 2004), Buchloe dactyloides (Gruntman and Novoplansky 2004), Glycine max (Gersani et al. 2001). Overall, the results from these studies show species-specific responses to self/non-self recognition.

Kin recognition studies in plants have expanded on self/non-self studies and have shown that kin recognition occurs not only in animals and microbes, but also in plants (Biedrycki and Bais 2010). Kin recognition could be advantageous when the recognition prevents costly competitive behavior toward kin and/or allows for cooperation to occur among siblings (Murphy and Dudley 2009). Consistent with research on animals, species specific responses are highly variable in kin recognition (Biedrzycki and Bais 2010). Here we outline the predominant kin recognition studies to date. (1) The first kin recognition study by Dudley and File (2007) showed that Cakile edentula plants grown in pots with strangers (seeds from the same population but different mothers) had more roots then plants grown with kin (Dudley and File 2007; Dudley and File 2008). Results from the $C$. edentula study resulted in immediate responses throughout the literature (Callaway and Mahall 2007; de Kroon 2007; Dudley and File 2008; Klemens 2008; Milla 
et al. 2009). (2) In two other species studied, opposite results were found in Impatiens pallida (Murphy and Dudley 2009) and Chenopodium album (Dudley et al. unpublished data) which showed that groups of siblings have higher root allocation then groups of strangers when direct root contact was present (Biedryzcki 2009). (3) The results of the kin recognition study with the species Lupinus angustifolius did not show evidence of kin recognition (Milla 2009). (4) Another kin recognition study was done by Biedrzycki et al (2009) in Arabisdopsis thaliana and showed that when seedlings were exposed only to the root exudates of another plant (KIN, STRANGER or OWN), STRANGER roots increased lateral root formation more than KIN or OWN (expected in kin recognition), whereas OWN seedlings had longer roots then either KIN or OWN (expected in self/nonself recognition).

The most recent kin recognition study, done by Biedrzyck et al 2009, had a novel way of addressing kin recognition. The study was based on whether root secretions (root exudates) could produce differences in the ability of a plant to recognize another plant as kin/self/or stranger in Arabidopsis thaliana (Biedrzycki et al. 2009). The term root exudation refers to the process of roots secreting small molecular weight compounds into the surrounding rhizopsphere (Bais et al. 2006). In the experiments performed by Biedrycki et al. (2009) instead of having roots physically exposed to one another, roots of one plant were exposed only to the media and any root exudates secreted from roots of another plant. The plants were grown in 24 well tissue culture plates with $1 \mathrm{ml}$ of MS media (1\% sucrose and $4.4 \mathrm{~g} / \mathrm{MS}$ media) (Murashige 1978). The A. thaliana study involved the exposure to exudates from multiple KIN, multiple STRANGER and OWN 
exudates and half of the plates were exposed to a secretion inhibitor (sodium

orthovanadate) which blocks the root secretion of several phenolic compounds (exudates) in A. thaliana (Loyola-Vargas). The results showed that plants exposed to STRANGER exudates had an increase in lateral root formation compared to plants exposed to their OWN or KIN exudates. Sodium orthovandate was able to remove the effect of the root exudates, resulting in KIN, STRANGER and OWN plants all producing the same number of lateral roots.

The Biedrycki et al. (2009) study was the backbone for the study we present here using the species Distichlis spicata. D. spicata is a salt-marsh grass, both a monocot and a perennial species, which have been suggested as two plant characteristics that need to be studied in order to further address the breadth of differences that can be found in KIN recognition studies in plant species (Biedrzycki et al. 2010). Distichlis spicata is a dioecious grass, separate sexes on separate plants, and the separate sexes occur in areas that are nearly $100 \%$ male and $100 \%$ female areas, called spatial segregation of the sexes (Eppley, 2006 and 2009). These sex-ratio biased areas have also been found to be significantly higher in phosphorus in female-majority areas and lower in phosphorus in male-majority areas (Eppley et al. 2009). In a recent field reciprocal transplant experiment, we tested the niche partitioning hypothesis for spatial segregation of the sexes in D. spicata. The niche partitioning hypothesis states that plants in inter-sexual competition are expected to have reduced fitness compared to plants in intra-sexual competition. Our results showed that plants in inter-sexual competition had significantly less overall biomass then plants in intra-sexual competition, accepting the niche 
partitioning hypothesis as a selective force for spatial segregation of the sexes (Mercer and Eppley 2009). These kin recognition studies have the potential to tease out not only how plant relationship effects roots but also how sexual competition (inter-sexual, intrasexual, or no competition) effects below ground, root interactions. The results of this study will help to further test the niche partitioning hypothesis as a force for SSS in Distichlis spicata.

The purpose of our experiment was to examine the response of D. spicata roots when exposed to liquid media (addition of root exudates and/ or subtraction of nutrients) previously occupied by another plant. We address the following questions: (1) Do $D$. spicata plants show plasticity in their root response depending on if the other plant is a KIN, STRANGER or OWN? (2) Do D. spicata plants show plasticity in their root response depending on if the other plant is an intra-sexual, inter-sexual competitor or has no competitor? In our study, we did not attempt to use the secretion inhibitor sodium orthovanadate as this inhibitor was used specifically for inhibiting exudates known to be exuded from Arabidopsis thalania (Loyola-Vargas et al. 2007) and because we do not know the root exudates released by D. spicata, the sodium orthovanadate could cause confounding results in our experiment.

\section{Materials and Methods}

\section{(A) Study species}

The study species used, Distichlis spicata (Poaceae) is a dioecious, clonal, perennial grass existing in salt-marsh habitats ranging on the east and west coast of North America 
(Hitchcock 1971). Sexual reproduction in D. spicata involves pollen dispersal by wind (Beetle 1943; Hitchcock 1971) and water and bird dispersal of seeds (S. Eppley, personal observations) with extensive asexual propagation of rhizomes(Beetle 1943; Hitchcock 1971). Previous studies have shown that males and females are spatially segregated in both Oregon and California salt-marshes called spatial segregation of the sexes (SSS) (Eppley 2000; Eppley 2001; Eppley 2005; Eppley 2006; Eppley et al. 2009a; Eppley et al. 1998b). We conducted the lab work for this study in a sterile culture room (sterile hood and growth chamber) at Portland State University. Seeds from Whalen Island in Pacific City, Oregon were collected October 2008.

\section{(B) Experimental Design}

This experiment was designed to test indirect contact of two plants by determining root response to liquid media. All measured seedlings were from the same population, Whalen Island and the same year, 2008. The three plant relationship treatments were OWN (control), KIN (sibling) and STRANGER (non-sibling). The experiment was also analyzed for inter-sexual, intra-sexual and no competition as each competing plant in KIN and STRANGER were also in inter- or intra-sexual competition and each OWN plant was either a single male or a single female. The total size of the experiment was 4 plates for STRANGER, 5 plates for KIN, 4 plates for OWN, approximately 5 seedlings were damaged per plate and were not recorded $(\mathrm{N}=244)$.

\section{(C) Culture Conditions}

All research as follows was performed in a sterile room using sterile technique under a 
UV-hood. D. spicata seeds (580 seeds total) were surface sterilized in 30\% bleach for 30 minutes, transferred to sterile $\mathrm{DiH}_{2} \mathrm{O}$ for 15 minutes and transferred to $\mathrm{EtOH}$ for 2 minutes and then let to air dry. Next the seeds were transferred sterilely to petri dishes $(100 \times 15 \mathrm{~mm})$ in low density with seeds from 21 mothers used for the KIN treatment and for the STRANGER and OWN the mothers were randomly mixed together and germinated 10-20 seeds per dish on petri plates with sterile Murashige and Skoog media (Sigma Alrdrich) at $4.4 \mathrm{~g} / \mathrm{L}$ (1\% agar, 3\% sucrose) and stored in the refrigerator for 7 days. Next plates germinated for 8 days under $\sim 320 \mathrm{micromol} / \mathrm{m} / \mathrm{s} \mathrm{light} \mathrm{at} \mathrm{(32 \%}$ humidity, 27.0 degrees Celsius) and were randomized daily. Following germination, plants were placed into 24 well culture plates with $1 \mathrm{ml} \mathrm{MS} \mathrm{liquid} \mathrm{media} \mathrm{(1 \%} \mathrm{sucrose).}$ Plates were placed onto a rotary shaker (90) rpm under fluorescent light $\sim 320$ $\mathrm{micromol} / \mathrm{m} / \mathrm{s} \mathrm{light}$ at 27 degrees $\mathrm{C}$. The rotary shaker was used to mix the liquid and to prevent hypoxia (Biedryzycki 2010). Plate order was randomized daily. The exudates source treatment was imposed for seven days.

\section{(D) Treatments}

Every other day for 7 days, for example KIN 1 plant and KIN 2 plant were picked out of well 1 and well 2 at the same time with forcepts. Next, KIN 1 was placed into well 2 and KIN 2 was placed into well 1, this continued every other day for seven days. The same procedure was used for STRANGER plants. Plants in the OWN treatment were lifted out of their well and then put back into their own well, as a control for handling. All exchanges were conducted under a UV sterilized hood to minimize contamination. Both STRANGER and KIN only experienced exudates from a paired plant and OWN only 
experienced exudates from itself.

\section{(E) Measurements}

Fifteen days after sowing, seedlings were removed from their wells and the number of lateral roots, the length of the longest root, the number of root hairs, total biomass and root/shoot ratios were measured for each plant. The biomass of the plant was measured after 6 days in the $60{ }^{\circ} \mathrm{C}$ drying oven. To determine the sex of the 244 plants, we used sex-specific molecular markers. Leaves were taken from each plant relative to the size of the plant (approximately 5-x-1 cm) and dried on silica gel. The plant samples were frozen at $4{ }^{\circ} \mathrm{C}$. We extracted DNA using the DNeasy Plant Mini Kit (Qiagen, Valencia, California) and followed the plant mini extraction protocol. The sex of each plant was determined using a set of D. spicata sex-specific STS markers, following Eppley et al. (2009). Sex was determined only if a 1062 bp control band was present and was considered female if there was a 317 bp band and male if no 317 bp band was present. The DNA extraction of 32 plants was not sufficient resulting in the inability to determine the sex of those plants; $(\mathrm{N}=212)$.

\section{Data Analysis}

We analyze the data on root/shoot ratio, total dry weight, number of root hairs, number of lateral root and root length for both relatedness (KIN, OWN, STRANGER) and sexual competition (INTRA, INTER, NONE). Although we could not put both the sexual competition and relatedness interactions into the same model because DF was limited, we analyzed a subset of the data without the OWN (or none) and found no significant interactions (results not shown). Therefore, we analyzed both sexual 
competition and relatedness separately. For relatedness, we used a One-way ANOVA and data were transformed to satisfy the assumptions of the ANOVA models; root/shoot (residuals not normal so transformed data with log transformation; variances equal), total weight (normal residuals and equal variances), root hairs (residuals normal, variances unequal; square root transformed), lateral roots (residuals normal/variances unequal, log transform) and root length (residuals normal/ variances unequal; inverse transform) (Day and Quinn 1989) (SAS Institute 2007). Bonferroni correction were performed for multiple comparisons. For sexual competition, we used a 2-way ANOVA and the model included competition, plant sex (sex) and the interaction of competition x sex. Significant main effects $(\mathrm{P} \leq 0.05)$ were analyzed further by pairwise post hoc comparisons. Bonferroni correction were performed for multiple comparisons and when interactions were found, Tukey's post hoc tests were performed.

\section{Results}

\section{Relatedness}

Data suggest that seedlings paired with more related seedlings had more lateral roots $(\mathrm{N}=$ 244; $P<0.0001 ; \mathrm{F}=12.56$; Table 4-1, Figure 4-1 A) and longer root length $(\mathrm{N}=244 ; \mathrm{P}=$ 0.006, F = 5.12; Table 5-1, Figure 5-1 B). There was no significant effect of relatedness on number of root hairs $(\mathrm{N}=244 ; \mathrm{P}=0.11, \mathrm{~F}=2.27)$, total dry weight $(\mathrm{N}=244 ; \mathrm{P}=$ $0.590 ; \mathrm{F}=0.70)$ or root/shoot ratio $(\mathrm{N}=244 ; \mathrm{P}=0.12 ; \mathrm{F}=2.21)$.

\section{Sexual Competition}

A plant with a competitor of the opposite sex (INTER) has significantly less total dry 
weight than a plant with no competitor (NONE) and a plant with a competitor of the same sex (intra-sexual competition, INTRA) $(\mathrm{N}=212 ; \mathrm{P}=0.003$; Table 4-2, Figure 4-2 A). Furthermore, a plant with the opposite sex was found to have significantly greater root/shoot ratio then either an intrasexual competitor or a plant without a competitor $(\mathrm{N}=$ 212, $P=0.01$; Table 4-2, Figure 4-2 B). No significant interaction was found for the effect of competition $\mathrm{x}$ sex (Table 4-1). For the effect of plant sex, total dry weight was the only trait measured showing a significant interaction, female plants were significantly heavier then male plants $(\mathrm{N}=212, \mathrm{P}=0.004$; Table 4-2).

\section{Discussion}

These data suggest that Distichlis spicata has a plastic root response to only the liquid media another plant's root has previously occupied. The design of this experiment allowed us to control for space because each plant was placed into a single well of the 24well plate. We were also able to control for the amount of nutrients by using a liquid homogenous nutrient solution, which is important as there has been controversy over the effects on space and nutrients in kin recognition experiments (Hess and De Kroon 2007). The measurements we took for the plants were all based on traits that are plastic in response to competition in plants; lateral root number has been shown to also be a nutrient dependent process in Arabidopsis (Malamy and Ryan 2001), length of the longest root (Biedrzycki et al. 2009), root/shoot ratio (Mercer and Eppley), total biomass (Mercer and Eppley) and number of root hairs which are important for water and nutrient absorbance. We found both the number of lateral roots and the longest root length was significantly greater for KIN compared to OWN or STRANGER (Figure 4-1). 
Belowground competition observed in D. spicata could be caused by two things: 1)

physical root interactions or 2) changing the environment (via addition of exudates and/or removing nutrients). The design of the experiment rules out physical interactions as the cause for belowground root competition and thus competition must be due to a change in the environment, although we are not able to distinguish between plants manipulating the sterile media by adding exudates and/or subtracting nutrients. Below, we discuss our results with respect to relatedness and inter-sexual competition.

\section{Kin recognition in a dioecious plant}

By analyzing the data in terms of relatedness, we were able to distinguish whether plants respond differently based on whether the other plant is a KIN, SELF, or STRANGER. We found that KIN plants had significantly greater lateral root number and root length then STRANGER or OWN (Figure 4-1 A and B). Biedrzycki et al (2009), in a similar experiment in Arabidopsis thaliana, found that the lateral root number was the same for both KIN and OWN and significantly higher for STRANGER plants; which showed a KIN/STRANGER recognition pattern. For root length, they found that OWN plants were significantly longer then KIN or STRANGER, showing a self/non-self recognition pattern (non-self are both the KIN and STRANGER). In contrast, our results showed that lateral root number was similar for both OWN and STRANGER and greater for KIN.

We have generated two explanations to explain why plants grown in media with its OWN exudates and with exudates from a STRANGER would appear the same: 1.) The STRANGER plants do not recognize one another and so respond to only their own 
exudates, causing similar results to be seen for both STRANGER and OWN or 2.) The STRANGER plants are inhibiting one another so they have less lateral roots and smaller root length. Interestingly though, total dry weight and root/shoot for OWN, STRANGER and KIN was not significantly different, suggesting that overall resource allocation is not compromised or distributed differently to roots versus shoot. The definition of root competition is the reduction of available nutrients to roots of one plant due to another plant (Shenck 2006) and an increase in the number of lateral roots has been shown to directly correlate with increases in nutrient availability (Hodge 2004). Because all plants were given the same starting volume of nutrients the results of the lateral root data could suggest that OWN plants and STRANGER plants are acquiring nutrients more quickly at the beginning of development. The total nutrients left in solution would be lower resulting in lateral roots not developing as quickly compared to KIN plants. KIN plants might not be taking up as many nutrients at the beginning and then as they grow the nutrients in solution are still relatively high and lateral roots can increase to acquire these nutrients. The lateral roots and root length could be increased in KIN so that nutrient acquisition is increased and total plant biomass is not compromised.

However, it has been proposed that not all interactions of roots are based on resources, and the interactions here could involve chemical signaling such as the suppression of neighboring roots with toxic compounds (Hodge 2004). This theory could suggest that the root length and number of lateral roots in STRANGER plants appear to be doing the same thing as OWN plants but in reality the STRANGER plants are producing chemicals which inhibit root growth. OWN plants would not need as many lateral roots because they are not inhibited by their own exudates and the KIN plant could 
be responding to the exudates by increasing the lateral root number and growing their primary root longer.

Inter-sexual competition

The results of this study show that plants in inter-sexual competition have significantly less biomass then plants in intra-sexual competition and no competition. Furthermore, the results show that plants in inter-sexual competition have significantly greater root/shoot ratio compared to plants in intra-sexual competition or plants in no competition. These results support the data we previously found in the field; our lab results show that plants can respond differentially to intra-versus inter-sexual competition from conspecifics (Mercer and Eppley 2009). Our results lends support to the niche partitioning hypothesis which suggests that competition between a female and male plant will reduce fitness more than competition between plants of the same sex (Figure 4-2 A and B) (Bierzychudek and Eckhart 1988), which is consistent with our field data (Mercer and Eppley). Furthermore this data gives an explanation as to why spatial segregation of the sexes occurs in D. spicata by lending support to the niche partitioning favoring plants of the opposite sex spatially segregating from one another to reduce competition.

\section{Conclusions}

The results of our study suggest that a plant can respond differently to another plant based on whether that plant is a KIN, OWN or a STRANGER. Furthermore, plants can respond differently if the other plant is an inter-sexual, intra-sexual or no competitor. The results 
we found in both analyses suggest that the differential responses are due to a changing the environment either by plants adding exudates into the surroundings and/or by plant removing nutrients. In order to determine whether root exudates and/or nutrients are the cause of the differences found, future studies will have to analyze the media for exudates and determine remaining nutrient content for sexual type and plant relationship. 
Table 4-1 Summary of ANOVA used to determine relatedness plant relatedness (KIN, STRANGER, OWN) on root/shoot ratio, total dry weight, root hairs, lateral roots and root length of root exudates trial after 7 days. $P$ values in bold are significant after the Bonferroni correction.

\begin{tabular}{lccc}
\hline Effect & \multicolumn{3}{c}{ Relatedness } \\
& df & F & P \\
& & & 0.12 \\
\hline Root/Shoot & 2 & 2.12 & 0.590 \\
Total Dry Weight & 2 & 0.70 & 0.11 \\
\# of Root Hairs & 2 & 2.27 & $<\mathbf{0 . 0 0 0 1}$ \\
\# of Lateral Roots & 2 & 12.75 & $\mathbf{0 . 0 0 6}$ \\
Root Length & 2 & 5.12 &
\end{tabular}


Table 4-2 Summary of ANOVA used to determine the effects of sexual competition (INTRA, INTER, NONE), plant sex (male or female) and the interaction of competition and plant sex on root/shoot ratio, total dry weight, root hairs, lateral roots and root length of root exudates trial after 7 days.

\begin{tabular}{|c|c|c|c|c|c|c|c|c|c|}
\hline \multirow[t]{2}{*}{ Effect } & \multicolumn{3}{|c|}{ Competition } & \multicolumn{3}{|c|}{$\underline{\text { Plant Sex }}$} & \multicolumn{3}{|c|}{ Competition x Sex } \\
\hline & $\mathrm{df}$ & $\mathrm{F}$ & $\mathrm{P}$ & $\mathrm{df}$ & $\mathrm{F}$ & $P$ & $\mathrm{df}$ & $\mathrm{F}$ & $\mathrm{P}$ \\
\hline Root/Shoot & 2 & 4.70 & 0.01 & 1 & 1.48 & 0.23 & 2 & 1.23 & 0.30 \\
\hline $\begin{array}{l}\text { Total Dry } \\
\text { Weight }\end{array}$ & 2 & 6.12 & 0.003 & 1 & 8.74 & 0.004 & 2 & 2.24 & 0.11 \\
\hline $\begin{array}{l}\text { \# of Root } \\
\text { Hairs }\end{array}$ & 2 & 2.09 & 0.13 & 1 & 0.08 & 0.78 & 2 & 1.48 & 0.23 \\
\hline $\begin{array}{l}\text { \# of Lateral } \\
\text { Roots }\end{array}$ & 2 & 2.62 & 0.08 & 1 & 2.79 & 0.10 & 2 & 0.29 & 0.75 \\
\hline $\begin{array}{l}\text { Root } \\
\text { Length }\end{array}$ & 2 & 1.99 & 0.14 & 1 & 2.10 & 0.15 & 2 & 1.45 & 0.24 \\
\hline
\end{tabular}


Figure 5-1 Graph of plant relatedness based on Lateral root number and Root length (mean $\pm \mathrm{SE}$ ) $\mathrm{N}=244$ after 7 days exposed to the sterile media of another root. The treatments employed for the relatedness analysis: OWN, plant in OWN exudates; KIN, plant in exudates of KIN; and STRANGER, plant in exudates of STRANGER from same population. Different letters indicate significant differences $(\mathrm{P}<0.05)$ among treatments.

Figure 5-2 Graph of sexual competition analysis based on significant data for Dry weight and root/shoot ratio (mean $\pm \mathrm{SE}$ ), $\mathrm{N}=212$ after 7 days exposed to the sterile media of another root grown in three competition treatments: None no competitor, Inter an intersexual competitor of the same species, or Intra an intra-sexual competitor of the same species. Different letters indicate significant differences $(\mathrm{P}<0.05)$ among treatments. 
Figure 4-1

A

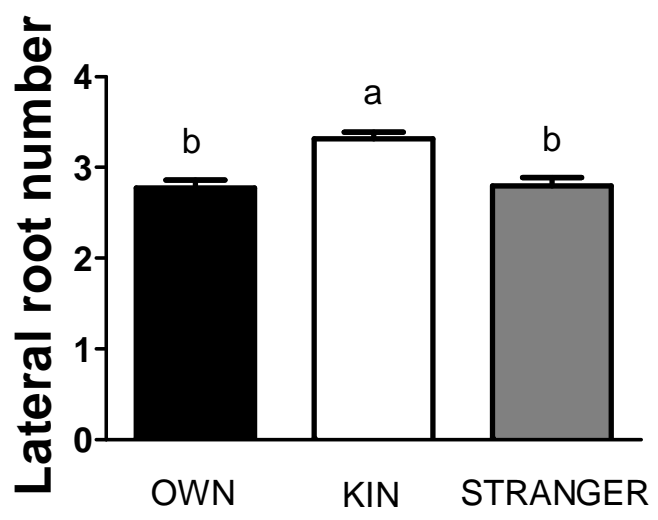

B

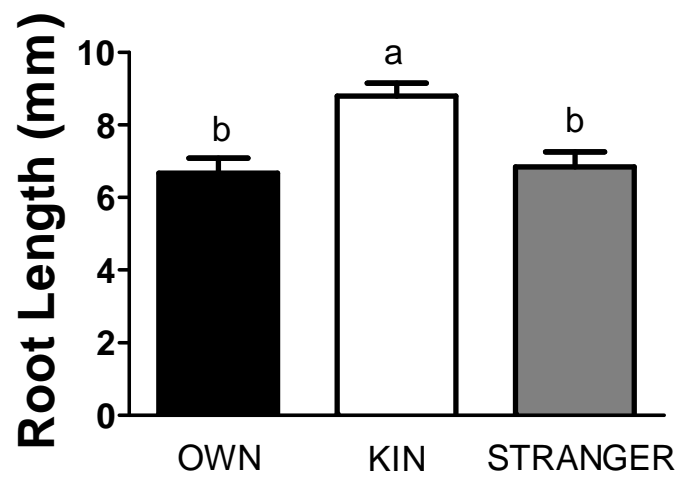


Figure 4-2

A

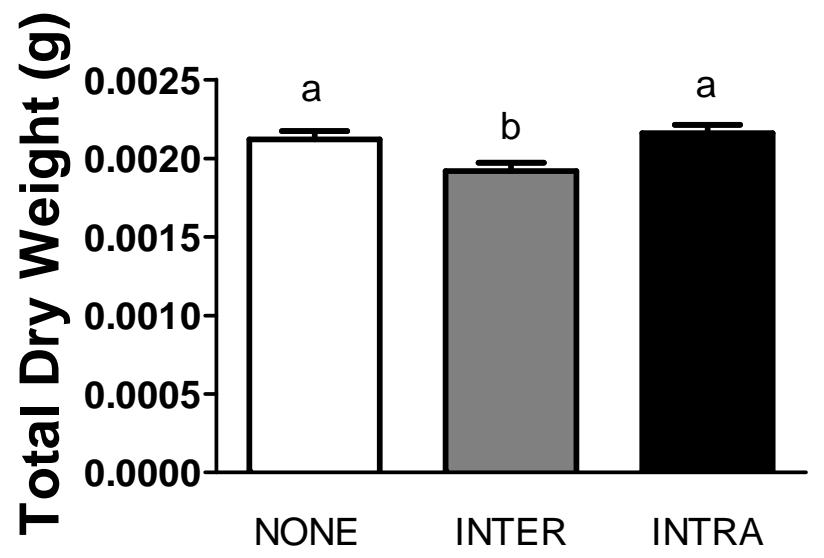

B

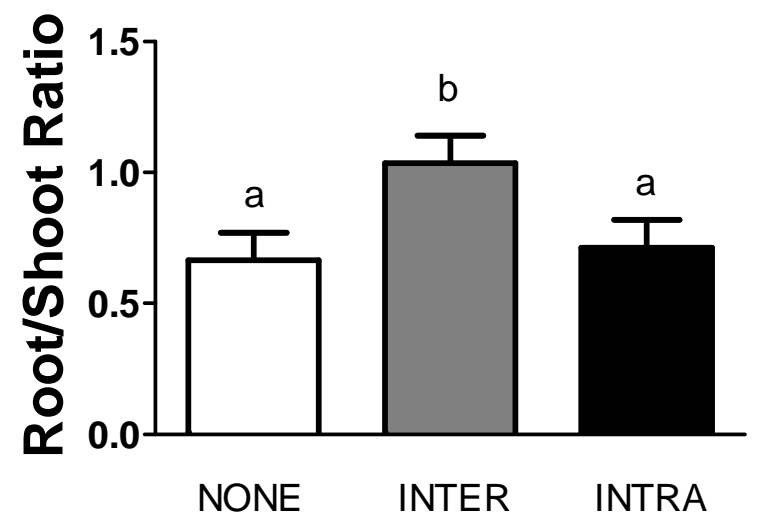




\section{Chapter 5: Conclusions}

Current and past research has aimed at understanding how different sexual systems are maintained. The focus of our research is on the dioecious sexual system which has shown that some male and female plants occur in different habitats, which can be physically separated from one another. When males and females spatially occur away from one another, in areas nearly $100 \%$ female and nearly $100 \%$ male, this is called spatial segregation of the sexes (SSS). If males and females are separated by space, this could decrease competition from males and females and/or allow for males and females to acquire different nutrients for reproduction from different habitats.

Our field study showed that Distichlis spicata does exhibit spatial segregation of the sexes in Oregon which is conducive to previous results found in California. The results we found for our study of native reproductive males and females found that females have higher fitness in female-majority sites which are also higher in phosphorus compared to male-majority habitats which are lower in phosphorus. Interestingly, reproductive males showed the same fitness response in both male-majority and female-majority habitats.

Next, via a reciprocal transplant experiment with competing plants in cones (intra, inter, none) into the field, we tested the niche partitioning hypothesis favoring spatial segregation of the sexes. Our data suggests that a plant in inter-sexual competition has significantly less biomass than an intra-sexual competitor. This supports the niche 
partitioning hypothesis suggesting that females and males compete more and so spatial segregation of the sexes would reduce competition between males and females.

The next step of our research was to determine how plants are competing. We used an experiment designed by Biedrzycki et al to test if only the liquid media plants are in contribute to plasticity in competition. Data was analyzed both for competition (INTRA, INTER and NONE) and plant relatedness (KIN, STRANGER and OWN). Our findings show that females and males compete significantly more than intra or no competition. The data show that KIN have significantly greater lateral root number and root length compared to STRANGER and OWN plants.

Both the field and lab experiments have helped improve our understanding of the mechanisms involved in how spatial segregation of the sexes can occur in dioecious plants. The data presented has shown similar results in both the field and the lab. Our results lends support to the niche partitioning hypothesis which suggests that competition between a female and male plant will reduce fitness more than competition between plants of the same sex. Furthermore this data gives an explanation as to why spatial segregation of the sexes occurs in D. spicata by lending support to the niche partitioning favoring plants of the opposite sex spatially segregating from one another to reduce competition. The lab data showed that males and females compete more when only subject to the nutrients and exudates of the other plant suggesting that inter-sexual competitors are either adding exudates into the surrounding media or taking out nutrients to cause a decrease in biomass. 
Currently we have a reciprocal transplant experiment in place, to reach sexual maturity, to test the empirically test the sexual specialization hypothesis. We also have begun a root exudates experiment with known mothers for all plants and furthermore, we have in place a study which will look at root carbon exudation differences in males and females. Future studies include using a nutrient and exudates analysis on the media plants are grown in. We have already developed a phosphorus assay and because we know that $\mathrm{P}$ is significantly different in male-majority and female-majority areas, this should be the first step in a nutrient analysis of liquid media. 


\section{References}

Ågren, J., K. Danell, T. Elmqvist, L. Ericson, AND J. Hjältén. 1999. Sexual dimorphism and biotic interactions. In M. A. Geber, T. E. Dawson, and L. F. Delph [eds.], Gender and sexual dimorphism in flowering plants, 217-246. Verlag-Springer, New York, New York, USA.

Allen, E. B., AND M. F. Allen. 1986. Water relations of xeric grasses in the field: Interactions of mycorrhizas and competition. New Phytologist 104: 559-571.

Allen, E. B., AND G. L. Cunningham. 1983. Effects of vesicular-arbuscular mycorrhizae on Distichlis spicata under three salinity levels. New Phytologist 93: 227-236.

Allsopp, N., AND W. D. Stock. 1992. Density dependent interactions between VA mycorrhizal fungi and even-aged seedlings of two perennial Fabaceae species. Oecologia 91: 281-287.

Azcon, R., AND J. A. Ocampo. 1981. Factors affecting the vesicular-arbuscular infection and mycorrhizal dependency of thirteen wheat cultivars. New Phytologist 87: 677-685.

Bach, C. E., B. A. Hazlett, AND D. Rittschof. 2006. Sex-specific differences and the role of predation in the interaction between the hermit crab, Pagurus longicarpus, and its epibiont, Hydractinia symbiolongicarpus. Journal of Experimental Marine Biology and Ecology 333: 181-189.

Bawa KS, Opler PA (1977) SPATIAL RELATIONSHIPS BETWEEN STAMINATE AND PISTILLATE PLANTS OF DIOECIOUS TROPICAL FOREST TREES. Evolution 31:64-68

Beetle A (1943) The North American variations of Distichlis spicata. Bull. Torrey Bot. Club 70:638

Bertiller MB, Sain CL, Bisigato AJ, Coronato FR, Aries JO, Graff P (2002) Spatial sex segregation in the dioecious grass Poa ligularis in northern Patagonia: the role of environmental patchiness. Biodiversity and Conservation 11:69-84

Bertness MD, Ellison AM (1987) Determinants of pattern in a New England marsh plant community. Ecological Monographs 57:129-147

Bertness MD, Wise C, Ellison AM (1987) Consumer pressure and seed set in a salt marsh perennial plant community. Oecologia 71:190-200

Biedrzycki ML, Jilany TA, Dudley SA, Bais HP (2009) Root secretions mediate kin recognition in plants. Plant Biology (Rockville) 2009:372

Bierzychudek P, Eckhart V (1988a) Spatial segregation of the sexes in dioecious plants. American Naturalist 132:34-43

Bohrer, K. E., C. F. Friese, AND J. P. Amon. 2004. Seasonal dynamics of arbuscular mycorrhizal fungi in differing wetland habitats. Mycorrhiza 14: 329-337.

Brazeau DA, Lasker HR (1992) Reproductive success in a marine benthic invertebrate, the Caribbean octocoral Briareum asbestinum. Mar Biol 114:157-163

Burczyk J, Adams WT, Shimiza JY (1996) Mating patterns and pollen dispersal in a natural knobcone pine (Pinus attenuata Lemmon.) stand. Heredity 77:251-260

Bustan A et al. (2005) Evaluation of saltgrass as a fodder crop for livestock. Journal of the science of food and agriculture 85:2077-2084

Callaway RM, Mahall BE (2007) Plant ecology - Family roots. Nature 448:145-147 
Carvalho, L. M., I. Caçador, AND M. A. Martins-Loução. 2001. Temporal and spatial variation of arbuscular mycorrhizas in salt marsh plants of the Tagus estuary (Portugal). Mycorrhiza 11: 303-309.

Casper BB, Jackson RB (1997) Plant competition underground. Annu Rev Ecol Syst 28:545-570

Christensen, R. 1990. Log-linear models. Springer-Verlag, New York, New York, USA.

Christman MA, James JJ, Drenovsky RE, Richards JH (2009) Environmental stress and genetics influence night-time leaf conductance in the C-4 grass Distichlis spicata. Functional Plant Biology 36:50-55

Clutton-Brock TH (1986) Sex ratio variation in birds. Ibis 128:317-329

Conn JS, Blum U (1981) Differentiation between the sexes of Rumex hastatulus in net energy allocation, flowering, and height. Bull Torrey Bot Club 108:446-455

Correia O, Díaz Barradas MC (2000) Ecophysiological differences between male and female plants of Pistacia lentiscus L. Plant Ecology 149:131-142

Cooke, J. C., AND M. W. Lefor. 1990. Comparison of vesicular-arbuscular mycorrhizae in plants from disturbed and adjacent undisturbed regions of coastal salt marshes in Clinton, Connecticut, USA. Environmental Management 14: 131-137.

Cox PA (1981) NICHE PARTITIONING BETWEEN SEXES OF DIOECIOUS PLANTS. American Naturalist 117:295-307

Daines RJ, Gould AR (1985) THE CELLULAR BASIS OF SALT TOLERANCE STUDIED WITH TISSUE-CULTURES OF THE HALOPHYTIC GRASS DISTICHLIS-SPICATA. Journal of Plant Physiology 119:269-280

Darwin C (1871) The descent of man and selection in relation to sex. D. Appleton and Company, New York, New York USA

Dawson TE, Bliss LC (1989) Patterns of water use and the tissue water relations in the dioecious shrub, Salix arctica: the physiological basis for habitat partitioning between the sexes. Oecologia 79:332-343

Dawson, T. E., AND M. A. Geber. 1999. Sexual dimorphism in physiology and morphology. In M. A. Geber, T. E. Dawson, and L. F. Delph [eds.], Gender and sexual dimorphism in flowering plants, 175-216. Springer-Verlag, New York, New York, USA.

Dawson TE, Ehleringer JR (1993) Gender-specific physiology, carbon isotope discrimination, and habitat distribution in Boxelder, Acer negundo. Ecology 74:798-815

Day RW, Quinn GF (1989) Comparisons of treatments after an analysis of variance in ecology. Ecological Monographs 59:433-463

Delph LF, Galloway LF, Stanton ML (1996) Sexual dimorphism in flower size. American Naturalist 148:299-320

Dudley LS (2006) Ecological correlates of secondary sexual dimorphism in Salix glauca (Salicaceae). American Journal of Botany 93:1775-1783

Dudley SA, File AL (2007) Kin recognition in an annual plant. Biol Lett 3:435-438

Eckhart, V. M. 1999. Sexual dimorphism in flowers and inflorescences. In M. A. Geber, T. E. Dawson, and L. F. Delph [eds.], Gender and sexual dimorphism in flowering plants, 123-148. Springer-Verlag, New York, New York, USA.

Eissenstat, D. M., AND E. I. Newman. 1990. Seedling establishment near large plants: 
Effects of vesicular arbuscular mycorrhizas on the intensity of plant competition. Functional Ecology 4: 95-99.

Eliades LA, Voget CE, Arambarri AM, Cabello MN (2007) Fungal communities on decaying saltgrass (Distichlis spicata) in Buenos Aires province (Argentina). Sydowia 59:227-234

Elsey-Quirk T, Middleton BA, Proffitt CE (2009) Seed Dispersal and Seedling Emergence in a Created and a Natural Salt Marsh on the Gulf of Mexico Coast in Southwest Louisiana, USA. Restoration Ecology 17:422-432

Eppley SM (2000) Intrapopulation sex ratio variation and sexual specialization in the dioecious grass Distichlis spicata. In: Department of Evolution and Ecology. University of California, Davis

Eppley SM (2001) Gender-specific selection during early life-history stages in the dioecious grass Distichlis spicata. Ecology 82:2022-2031

Eppley SM (2006) Females make tough neighbors: sex-specific competitive effects in seedlings of a dioecious grass. Oecologia 146:549-554

Eppley SM, Mercer CA, Haaning C, Graves CB (2009a) SEX-SPECIFIC VARIATION IN THE INTERACTION BETWEEN DISTICHLIS SPICATA (POACEAE) AND MYCORRHIZAL FUNGI. American Journal of Botany 96:1967-1973

Eppley SM, O'Quinn R, Brown AL (2009b) New sequence-tagged site molecular markers for identification of sex in Distichlis spicata. Molecular Ecology Resources 9:1373-1374

Eppley SM, Stanton ML, Grosberg RK (1998a) Intrapopulation sex ratio variation in the salt grass Distichlis spicata. American Naturalist 152:659-670

Facelli, E., J. M. Facelli, S. E. Smith, AND M. J. McLaughlin. 1999. Interactive effects of arbuscular mycorrhizal symbiosis, intraspecific competition and resource availability on Trifolium subterraneum cv. Mt. Barker. New Phytologist 141: 535547.

Falik O, Reides P, Gersani M, Novoplansky A (2003) Self/non-self discrimination in roots. J Ecol 91:525-531

Finlay, R., AND B. Söderström. 1992. Mycorrhiza and carbon flow to the soil. In M. F. Allen [ed.], Mycorrhizal functioning: An integrative plant-fungal process, 134160. Chapman and Hall, New York, New York, USA.

Fisher R (1930) The genetical theory of natural selection, 2nd edn. Clarendon Press, Oxford

Freeman DC, Doust JLL, El-Keblawy A, Miglia KJ, McArthur ED (1997) Sexual specialization and inbreeding avoidance in the evolution of dioecy. Botanical Review 63:65-92

Freeman, D. C., L. G. Klikoff, AND K. T. Harper. 1976. Differential resource utilization by the sexes of dioecious plants. Science 193: 597-599.

Geber, M. A., T. E. Dawson, AND L. F. Delph. 1999. Gender and sexual dimorphism in flowering plants. Springer-Verlag, New York, New York, USA.

Gehring, C. A., AND T. G. Whitham. 1992. Reduced mycorrhizae on Juniperus monosperma with mistletoe: The influence of environmental stress and tree gender on a plant parasite and a plant fungal mutualism. Oecologia 89: 298-303.

Gersani M, Brown JS, O'Brien EE, Maina GM, Abramsky Z (2001) Tragedy of the 
commons as a result of root competition. Journal of Ecology 89:660-669

Gruntman M, Novoplansky A (2004) Physiologically mediated self/non-self discrimination in roots. Proc Natl Acad Sci USA 101:3863-3867

Hamilton WD (1967) Extraordinary sex ratios. Science 156:477-488

Hardy ICW (2002) Sex ratios: concepts and research methods. Cambridge University Press, Cambridge

Heckman, J. R., AND J. S. Angle. 1987. Variation between soybean cultivars in vesicular arbuscular mycorrhiza fungi colonization. Agronomy Journal 79: 428-430.

Hemborg, Å. M., AND W. J. Bond. 2005. Different rewards in female and male flowers can explain the evolution of sexual dimorphism in plants. Biological Journal of the Linnean Society 85: 97-109.

Hess L, De Kroon H (2007) Effects of rooting volume and nutrient availability as an alternative explanation for root self/non-self discrimination. Journal of Ecology 95:241-251

Hitchcock AS (1971) Manual of the grasses of the United States. Dover, New York, New York USA

Hodge A (2004) The plastic plant: root responses to heterogeneous supplies of nutrients. New Phytologist 162:9-24

Hodge A (2006) Plastic plants and patchy soils. Journal of Experimental Botany 57:401 411

Hodge A (2009) Root decisions. Plant Cell and Environment 32:628-640

Hoefnagels, M. H., S. W. Broome, AND S. R. Shafer. 1993. Vesicular-arbuscular mycorrhizae in salt marshes in North Carolina. Estuaries 16: 851-858.

Holzapfel C, Alpert P (2003) Root cooperation in a clonal plant: connected strawberries segregate roots. Oecologia 134:72-77

Huante P, Rincon E, Chapin FS (1998) Foraging for nutrients, responses to changes in light, and competition in tropical deciduous tree seedlings. Oecologia 117:209216

Hunter A, Morris NMB, Lafabrie C, Cebrian J (2008) Effects of nutrient enrichment on Distichlis spicata and Salicornia bigelovii in a marsh salt pan. Wetlands 28:760 775

Iglesias, M. C., AND G. Bell. 1989. The small-scale spatial distribution of male and female plants. Oecologia 80: 229-235.

Johnson, N. C., J. H. Graham, AND F. A. Smith. 1997. Functioning of mycorrhizal associations along the mutualism-parasitism continuum. New Phytologist 135: $575-585$.

Johnson-Green, P. C., N. C. Kenkel, AND T. Booth. 1995. The distribution and phenology of arbuscular mycorrhizae along an inland salinity gradient. Canadian Journal of Botany 73: 1318-1327.

Ketchum REB, Warren RS, Klima LJ, Lopezgutierrez F, Nabors MW (1991) THE MECHANISM AND REGULATION OF PROLINE ACCUMULATION IN SUSPENSION CELL-CULTURES OF THE HALOPHYTIC GRASS DISTICHLIS-SPICATA L. Journal of Plant Physiology 137:368-374

Kiehl K, Esselink P, Bakker JP (1997) Nutrient limitation and plant species composition in temperate salt marshes. Oecologia 111:325-330 
Korpelainen, H. 1991. Sex ratio variation and spatial segregation of the sexes in populations of Rumex acetosa and R. acetosella (Polygonaceae). Plant Systematics and Evolution 174: 183-195.

Koske, R. E., AND J. N. Gemma. 1989. A modified procedure for staining roots to detect VA mycorrhizas. Mycological Research 92: 486-505.

Levitan DR, Sewell MA, Chia F-S (1992) How distribution and abundance influence fertilization success in the sea urchin Strongylocentrotus franciscanus. Ecology $73: 248-254$

Li C, Ren J, Luo J, Lu R (2004) Sex-specific physiological and growth responses to water stress in Hippophae rhamnoides L. populations. Acta Physiologiae Plantarum 26:123-129

Lokker C, Susko D, Lovettdoust L, Lovettdoust J (1994) POPULATION GENETIC STRUCTURE OF VALLISNERIA-AMERICANA, A DIOECIOUS CLONAL MACROPHYTE. American Journal of Botany 81:1004-1012

Lovett-Doust J, O'Brien G, Lovett-Doust L (1987) Effect of density on secondary sex characteristics and sex ratio in Silene alba (Caryophyllaceae). Am J Bot 74:40-46

Mahall BE, Callaway RM (1991) ROOT COMMUNICATION AMONG DESERT SHRUBS. Proceedings of the National Academy of Sciences of the United States of America 88:874-876

Malamy JE, Ryan KS (2001) Environmental regulation of lateral root initiation in Arabidopsis. Plant Physiology 127:899-909

Marcum KB, Yensen NP, Leake JE (2007) Genotypic variation in salinity tolerance of Distichlis spicata turf ecotypes. Australian Journal of Experimental Agriculture 47:1506-1511

Marschner, H., AND B. Dell. 1994. Nutrient uptake in mycorrhizal symbiosis. Plant and Soil 159: 89-102.

McConnaughay KDM, Bazzaz FA (1991) Is physical space a soil resource. Ecology 72:94-103

Mcdonald KB, Barbour MB (1974) Beach and salt marsh vegetation of the North American Pacific coast. In: Reimold R, Queen WH (eds) The ecology of halophytes. Academic, New York, pp 175-233

McGonigle, T. P., M. H. Miller, D. G. Evans, G. L. Fairchild, AND J. A. Swan. 1990. A new method which gives an objective measure of colonization of roots by vesicular-arbuscular mycorrhizal fungi. New Phytologist 115: 495-501.

McKenney, M. C., AND D. L. Lindsey. 1987. Improved method for quantifying endomycorrhizal fungi spores from soil. Mycologia 79: 779-782.

Meagher TR (1984a) SEXUAL DIMORPHISM AND ECOLOGICAL DIFFERENTIATION OF MALE AND FEMALE PLANTS. Annals of the Missouri Botanical Garden 71:254-264

Meagher TR (1984b) Sexual dimorphism and ecological differentiation of male and female plants. Annals of the Missouri Botanical Garden 71:254-264

Mercer C, Eppley S Inter-sexual competition in a dioecious grass. Oecologia:1-8

Miller, R. M., AND J. D. Jastrow. 2000. Mycorrhizal fungi influence soil structure. In Y. Kapulnik, and D. D. Douds [eds.], Arbuscular mycorrhizas: Physiology and function, 3-18. Kluwer, Dordrecht, Netherlands. 
Moora, M., AND M. Zobel. 1998. Can arbuscular mycorrhiza change the effect of root competition between conspecific plants of different ages? Canadian Journal of Botany 76: 613-619.

Mullen, R. B., AND S. K. Schmidt. 1993. Mycorrhizal infection, phosphorus uptake and phenology in Ranunculus adoneus: Implications for the functioning of mycorrhizae in alpine systems. Oecologia 94: 229-234.

Murashige T (1978) CITATION CLASSIC - REVISED MEDIUM FOR RAPID GROWTH AND BIOASSAYS WITH TOBACCO TISSUE-CULTURES. Current Contents: $10-10$

Newman, E. I., AND P. Reddell. 1987. The distribution of mycorrhizas among families of vascular plants. New Phytologist 106: 745-751.

Newsham, K. K., A. H. Fitter, AND A. R. Watkinson. 1995. Multi-functionality and biodiversity in arbuscular mycorrhizas. Trends in Ecology \& Evolution 10: 407411.

Ngai JT, Jefferies RL (2004) Nutrient limitation of plant growth and forage quality in Arctic coastal marshes. J Ecol 92:1001-1010

Pietikäinen, A., AND M.-M. Kytöviita. 2007. Defoliation changes mycorrhizal benefit and competitive interactions between seedlings and adult plants. Journal of Ecology 95: 639-647.

Putwain PD, Harper JL (1972) Studies in the dynamics of plant populations V. Mechanisms governing the sex ratio of Rumex acetosa and $R$. acetosella. $\mathrm{J}$ Ecol 60:113-129

Rottenberg A (1998) Sex ratio and gender stability in the dioecious plants of Israel. Botanical Journal of the Linnean Society 128:137-148

Sargeant, M. R., C. Tang, AND P. W. G. Sale. 2008. The ability of Distichlis spicata to grow sustainably within a saline discharge zone while improving the soil chemical and physical properties. Australian Journal of Soil Research 46: 37-44.

SAS Institute (2007) JMP for Windows. Release 7.0.1. In, Cary, N.C.

Schenk HJ (2006) Root competition: beyond resource depletion. Journal of Ecology 94:725-739

Semchenko M, John EA, Hutchings MJ (2007) Effects of physical connection and genetic identity of neighbouring ramets on root-placement patterns in two clonal species. New Phytol 176:644-654

Shea, M. M., P. M. Dixon, AND R. R. Sharitz. 1993. Size differences, sex ratio, and spatial distribution of male and female water tupelo, Nyssa aquatica (Nyssaceae). American Journal of Botany 80: 26-30.

Shumway, D. L., AND R. T. Koide. 1995. Size and reproductive inequality in mycorrhizal and nonmycorrhizal populations of Abutilon theophrasti. Journal of Ecology 83: 613-620.

Singh, C., A. K. Sharma, AND B. N. Johri. 2002. Host genotype determines the impact of soil phosphorus on arbuscular mycorrhizal symbiosis in maize (Zea mays L.). Symbiosis 33: 145-164.

Silvertown J, Gordon DM (1989) A FRAMEWORK FOR PLANT BEHAVIOR. Annual Review of Ecology and Systematics 20:349-366

Slatkin M (1984) Ecological causes of sexual dimorphism. Evolution 38:622-630 
Smith, K. P., AND R. M. Goodman. 1999. Host variation for interactions with beneficial plant-associated microbes. Annual Review of Phytopathology 37: 473-491.

Smouse, P. E., AND T. R. Meagher. 1994. Genetic analysis of male reproductive contributions in Chamaelirium luteum (L.) Gray (Liliaceae). Genetics 136: 313 322.

Stark, L. R., D. N. McLetchie, AND B. D. Mishler. 2005. Sex expression, plant size, and spatial segregation of the sexes across a stress gradient in the desert moss Syntrichia caninervis. Bryologist 108: 183-193.

Stenlund, D. L., AND I. D. Charvat. 1994. Vesicular arbuscular mycorrhizae in floating wetland mat communities dominated by Typha. Mycorrhiza 4: 131-137.

Treseder, K. K. 2004. A meta-analysis of mycorrhizal responses to nitrogen, phosphorous, and atmospheric CO2 in field studies. New Phytologist 164: 347355.

Treseder, K. K., AND P. M. Vitousek. 2001. Effects of soil nutrient availability on investment in acquisition of $\mathrm{N}$ and $\mathrm{P}$ in Hawaiian rain forests. Ecology 82: 946954.

van Duin, W. E., J. Rozema, AND W. H. O. Ernst. 1990. Seasonal and spatial variation in the occurrence of vesicular-arbuscular (VA) mycorrhiza in salt marsh plants. Agriculture Ecosystems \& Environment 29: 107-110.

Tyler G (1967) On the effect of phosphorus and nitrogen supplied to Baltic shore meadow vegetation. Bot Notiser 120:433-447

Varga, S., AND M.-M. Kytöviita. 2008. Sex-specific responses to mycorrhiza in a dioecious species. American Journal of Botany 95: 1225-1232.

Valiela I, Teal JM (1974) Nutrient limitation in salt marsh vegetation. In: Reimold RJ, Queen WH (eds) Ecology of halophytes. Academic, New York, pp 547-563

Verdu M, Villar-Salvador P, Garcia-Fayos P (2004) Gender effects on the post-facilitation performance of two dioecious Juniperus species. Functional Ecology 18:87-93

Wade KM (1981) Experimental studies on the distribution of the sexes of Mercurialis perennis L. III. Transplanted populations under light screens. New Phytol 87:447455

Watson EB, Byrne R (2009) Abundance and diversity of tidal marsh plants along the salinity gradient of the San Francisco Estuary: implications for global change ecology. Plant Ecol 205:113-128

West SA, Reece SE, Sheldon BC (2002) Sex ratios. Heredity 88:117-124

Yao, Q., X. L. Li, AND P. Christie. 2001. Factors affecting arbuscular mycorrhizal dependency of wheat genotypes with different phosphorus efficiencies. Journal of Plant Nutrition 24: 1409-1419. 